\title{
ARMEROS MILANESES EN NAVARRA: LA PRODUCCIÓN DE EUGUI*
}

\author{
POR \\ JOSÉ-A. GODOY
}

\section{RESUMEN - ABSTRACT}

Felipe III ordenó en 1595 el establecimiento en Eugui (Navarra) de un grupo de armeros milaneses especializados en el arte de la armadura. Las principales obras se produjeron sin embargo durante el reinado de Felipe III. Se estudia detenidamente la manufactura de Eugui, sus marcas, obras, las circunstancias de sus trabajos y sus relaciones laborales.

In 1595, Philip II summoned a group of Milanese armourers to settle in Eugui (Navarre). Their main work was produced undes Philip III. This paper studies these armourers, their trademarks, creations, working conditions and relationships

\section{PALABRAS CLAVE - KEY WORDS}

Armas y armaduras. Armeros. Centros de producción. Eugui. Marcas. Felipe III. Real Armería. Madrid.

Arms and armor. Production centres. Eugui. Trademarks. Philip III. Real Armería. Madrid.

La mención de la existencia de la armería de Pamplona aparece ya en el primer catálogo impreso de la Real Armería de Madrid, publicado en 1793 por Ignacio Abadia ${ }^{1}$ En la introducción, sin paginar, que precede la escueta y rápida enumeración de las armas y armaduras conservadas en dicha colección, se cita entre los centros de producción españoles: «Pamplona, en donde se hicieron para el Rey D. Felipe III dos Armaduras de muy bello gusto». Años más tarde, en 1849, Antonio Martínez del Romero realizó un nuevo catálogo ${ }^{2}$, mucho más extenso e importante, consagrado a la Real Armería. En él, el autor vincula un grupo de ocho armaduras y un arcabuz a la producción de Pamplona y una rodela a la del centro armero de

* La redacción de este artículo se remonta a 1986 para las actas del seminario sobre L'Armadura italiana del secondo cinquecento (c. 1540-c. 1610) celebrado dicho año en Florencia. Un año más tarde, publiqué en Reales Sitios $\left(\mathrm{n}^{\circ} 94,1987\right)$ un segundo artículo sobre este tema titulado Dos armaduras de Eugui para el Rey Felipe III (1598-1621) que es, en parte, un complemento de este. Desgraciadamente, a pesar de la voluntad de su organizador, Lionello G. Boccia, dichas actas no pudieron publicarse. El texto original ha sufrido muy pocos cambios: añadidura del párrafo final sobre las marcas de los armeros que hemos encontrado recientemente en el interior de las armaduras B 13-16, B 18-20 y algunas referencias bibliográficas suplementarias.

1 Resumen sacado del Inventario General Histórico que se hizo en el año de 1793 de los arneses antíguos, armas blancas y de fuego, con otros efectos de la Real Armería del Rey Nuestro Señor, Madrid, 1793.

2 Catálogo de la Real Armería mandado formar por S.M. siendo director general de reales caballeriza, armería y yeguada, el Excmo. Señor Don José Maria Marchesi, Madrid, 1849 
«Euqui» (sic) en Navarra. Dos de las armaduras citadas $(2411$, 2488, 531, 2486) estaban destinadas al rey Felipe III, mientras que las otras seis, de niños, pertenecían a sus tres hijos, don Felipe, don Carlos y don Fernando $(821,838,839,853,869,879)^{3}$; el arcabuz (1949) era un regalo del Virrey de Navarra al príncipe don Felipe, el futuro Felipe IV; y la rodela (1145), una obra presentada a este mismo rey por los armeros de Eugui. Sin embargo, nada permite pensar que la armadura $n^{\circ} 2411$ (A 347) y la rodela $n^{\circ} 1145$ (D 72) perteneciesen a estos centros armeros que Martínez del Romero creyó distintos e independientes.

Cuarenta y nueve años después, Valencia de Don Juan (Juan Bautista Crooke y Navarrot) publicó en 1898, su famoso «Catálogo histórico-descriptivo de la Real Armería». Valencia de Don Juan descartó del elenco Eugui-Pamplona, la armadura y la rodela citadas (A 347, D 72), remplazándolas por la armadura A 354-355 y la rodela D 73; esta última, pareja del morrion H 233 del Musée de l'Armée de París. Tanto Ignacio Abadía, como Martínez del Romero y Valencia de Don Juan, basaban sus atribuciones en las indicaciones encontradas en los antiguos inventarios de la Real Armería. La selección de Valencia de Don Juan conservada por su sucesor en la dirección de la Real Armería, José María Florit y Arizcún ${ }^{4}$, es la que ha perdurado hasta época reciente, es decir: la rodela D 73 con el morrión citado que serían productos de Eugui, mientras que Pamplona asumiría la paternidad de todas las otras armas y armaduras enumeradas. No obstante, esta lista siguió ampliándose con el tiempo gracias a José María Florit, quién emitió ciertos paraceres, que divulgados por Bashford Dean $(1911,1914)^{5}$ y Charles Relly Beard $(1924)^{6}$ influenciaron un poco la literatura especializada. De esta manera se llegó a vincular, sin un sólido fundamento, algunas obras típicamente de Italia septentrional — como las del «Maestro dal Castello» (c. 1590-1620) — a la producción de Pamplona. Encontramos un eco de esta tradición en el estudio consagrado por Stephen Grancsay (1974) a la armadura llamada del Duque de Medina Sidonia, hoy en la Walters Art Gallery de Baltimore ${ }^{7}$.

Curiosamente, la armadura que más ha hecho hablar de Eugui, tiene pocas probabilidades de haber sido forjada en este centro armero. Se trata de la armadura conocida como del Marqués de Leganés, don Diego Felipe de Guzmán, conservada en la Armeria Reale de Torino (B 44). Angelo Angelucci nos cuenta con detalle, en su catálogo de esta colección (1890), como llegó a conocer al propietario de dicha armadura y su lugar de fabricación a través del conocido armero español Eusebio Zuluaga, quién a su paso por Torino, en 1875, reconoció la armadura y le dejó la siguiente notificación: «Armadura del marques de Leganes, construida en Pamplona (Navarra)» ${ }^{8}$. Esta armadura de gran corpulencia, adornada con enigmáticas $« F »$, coronas con palmas y estrellas de cinco puntas, atrajo también la atención de Charles Buttin (1856-1931) quién le dedico un estudio monográfico ${ }^{9}$, publicado póstumamente en 1957. El principal mérito de este estudio reside en haber llegado a establecer que las armaduras atribuídas a Pamplona, debían de haber sido en realidad fabricadas en Eugui. Para ello, Charles Buttin se basó en un libro publicado en Pamplona en 1628: «Historia

3 A propósito de estas armaduras, Martínez del Romero comete un extraño lapsus al confundir Felipe IV con Felipe III: «Hiciéronse estas armaduras en Pamplona por mandado de Felipe III cuando era príncipe, para su uso y el de los príncipe D. Carlos y D. Fernando», op. cit., pág. 34.

4 «Armas artísticas españolas», en: Por el Arte, 1913, n 6, págs 19-21. Aunque confuso y con errores, señalamos aquí la existencia de un artículo de Julio Altadill donde se evocan las armaduras de Eugui-Pamplona conservadas en la Real Armería de Madrid: «Arneses, armaduras y objetos de armería confeccionados en Navarra», en: Boletin de la Comisíón de Monumentos Históricos y Artísticos de Navarra, 1934, t. XVIII, págs 324-329.

5 Catalogue of a Loan Exhibition of Arms and Armors, Nueva York, 1911, pág. 21, $\mathrm{n}^{\circ} 27$; The Collection of Arms and Armor of Rutherfurd Stuyvesant, 1914, págs 21-22, ${ }^{\circ} 16$.

6 Notes on The Barberini and allied armours, Blackburn, 1924, págs 33-35.

7 «An Historical Spanish Suit of Armour», en: Apollo, noviembre 1974, págs 64-68.

8 Catalogo della Armeria Reale, Torino, 1890, pág. 101.

9 «L'armure du marquis de Leganès, Turin, Armeria Reale», en: Armes Anciennes, 1957, nº 8, págs 3-16. 
Apologetica y descripcion del Reyno de Navarra [...]»10. En esta obra, se indica claramente el papel empleado por la «Ciudad y Ciudadela de Pamplona, con tanta abundancia de todas municions y armas que ay en ellas, que [...] es un Almagazen y plaça de armas, de donde se provee y embia en abundancia a otros muchos Presidios y plaças fuertes y exercitos, y armadas», y también el de la «Herreria de Eugui, que es un bolcan de fuego, donde se labra y haze mucha fundicion de peloteria, y balas de artilleria, coseletes, y celadas gravadas, rodelas, y otros generos de armas» ${ }^{11}$. En lo que se refiere a la armadura del Marqués de Leganés que Charles Buttin sitúa hacia 1635-1640, su origen y fecha fueron posteriormente discutidos ${ }^{12}$, llegándose a la conclusión de que dicha armadura es en realidad italiana y datable hacia 1627. Sin embargo, el propietario ha seguido considerándose don Diego Felipe de GuzMán, marqués de Leganés, cuyo nombre y título estaría evocado respectivamente por las $\langle\mathrm{F}\rangle \mathrm{y}$ coronas con palmas que aparecen en dicha armadura. Este razonamiento siempre nos pareció extraño, ya que resultaba difícil pensar que Diego Felipe de Guzmán, hubiera utilizado su segundo nombre Felipe en detrimento del primero, Diego, y también que lo emplease acompañado de la corona en lugar de serlo de su apellido, o, aún más, de su título nobiliario. En realidad, esta interesante armadura de Torino, cuyo peto de refuerzo se conserva en el Metropolitan Museum of Art de Nueva York (14.25.867), perteneció a otro noble español: don Gómez Suárez de Figueroa y Cordoba, Duque de Feria (1587-1634) y gobernador del Milanesado entre 1618-1625 y 1631-1633. De este general español existe otra armadura con su escarpa militar en el Museo del Ejército de Madrid ${ }^{13}$, y un par de pistolas de rueda dispersas entre Nueva York (Metropolitan Museum of Art, 14.25.1426) y Leeds (Royal Armouries, XII-731 $)^{14}$, que poseen los mismos motivos decorativos a base de «F», coronas con palmas y estrellas de cinco puntas. La prueba de que dichas armaduras y pistolas pertenecieron al Duque de Feria, se haya en dos cuadros del Museo del Prado, pintados en 1643 por Vicente Carducho: «La Expugnación de Rheinfelden» y el «Socorro de la plaza de Constanza». En ellos aparece el Duque llevando una armadura milanesa diferente a las citadas de Torino-Nueva York y Madrid. Sin embargo, su pantalón y escarpa de mando llevan bordados: las «F», las coronas con palmas y las estrellas de cinco puntas. Obviamente, la persona que hace bordar su ropa y escarpa con dichos motivos, también procura ponerlos con evidencia sobre sus armaduras.

En resumen, Ignacio Abadía (1793), Martínez del Romero (1849), Valencia de Don Juan (1898) y José María Florit (1905) mencionaron en sus escritos armas y armaduras fabricadas en Pamplona y Eugui en Navarra, noticia que poseían a partir de los inventarios antiguos $(1603 / 8,1625 / 6)$ de la Real Armería. Todos ellos creyeron en la existencia de dos centros de fabricación diferentes y se limitaron a proponer la identificación de tal o cual pieza, con más o menos éxito, y la indicación de origen señalada en los inventarios.

10 Ibid. Charles Buttin indica como autor del libro a Adan de Sada, quien firma bajo el seudónimo de don Garcia de Góngora y Torreblanca. En realidad se trata de Juan Sada y Amezqueta como se indica en la obra del Padre Antonio Pérez Goyena (S. J.), Ensayo de Bibliografia Navarra desde la creación de la imprenta en Pamplona hasta el año 1910, Burgos, 1949, t. II, $\mathrm{n}^{\circ} 413$.

11 Op. cit., libro I, pág. 3.

12 Thomas, Bruno y GAMBer, Ortwin (1958): «L'arte milanese dell'armatura», en: Storia di Milano, vol. XI, Milano, págs 825-826; BocCIA, Lionello G. y COELHo, Eduardo T. (1974): L'arte dell'armatura en Italia, Milano, págs 525 y 530, n ${ }^{\text {os }} 430 / 436$ y 438/439; DONDI, Giorgio y CARTESEGNA, Marisa (1982): «Illustrazione al catalogo y Schede critiche di catalogo», en: L'Armeria Reale di Torino, Milan, pág. 339, $\mathrm{n}^{\text {os }} 49-49 \mathrm{a}$.

13 Godoy, José-A. (1997): «Las armaduras de la Casa Ducal de Medinaceli, colección del Museo del Ejército, en: Militaria, revista de cultura militar», $n^{\circ} 9$, pág. I41, figs 5 y 6.

14 FFoulKes, Charles J. (1916): Inventory and Survey of the Armouries of the Tower of London, London, vol. II, págs 408-409; TARASSUK, Leonid (1986): «The Cabinet d'Armes of Louis XIII: Some Firearms and Related Problems», en: Metropolitan Museum Journal, vol. 21, págs 80-84, n 217. 


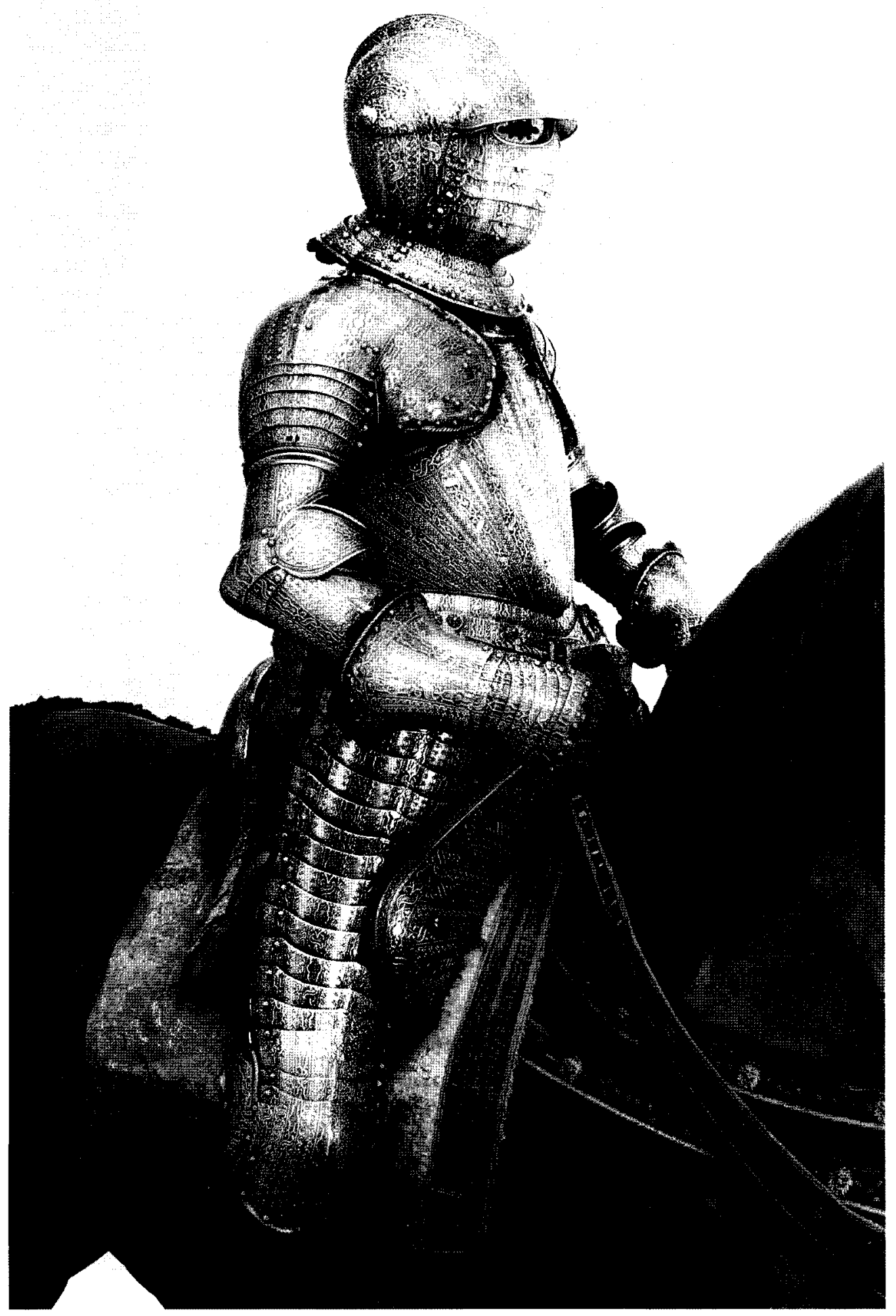

Fig. 1. Armadura de a caballo de Felipe III (Madrid, Real Armería, A 350) 


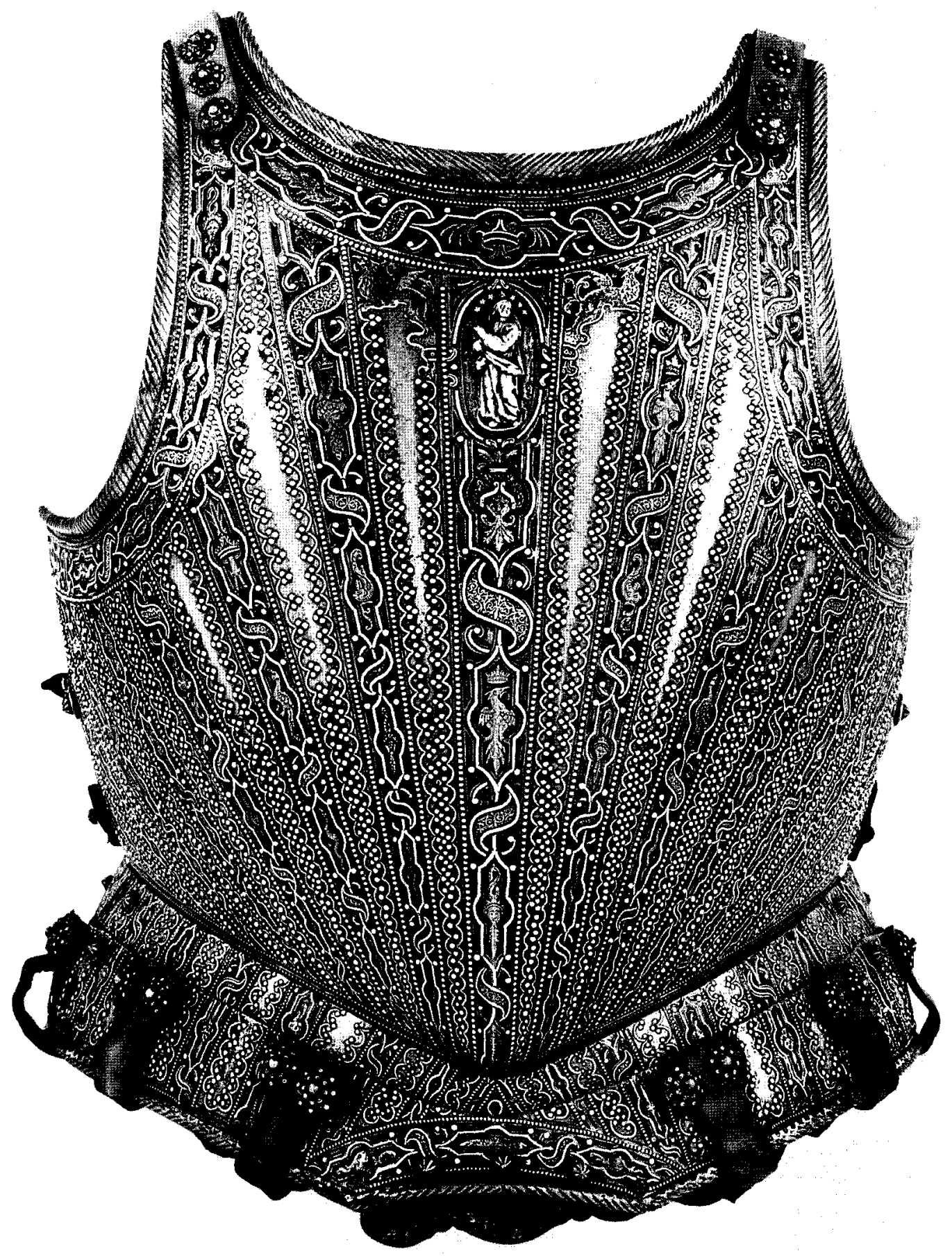

Fig. 2. Peto de la armadura A 350 de Felipe III 
Las armas y armaduras de la Real Armería que hemos enumerado anteriormente, están todas estrechamente vinculadas a la Casa Real española. Se trata de armas de lujo o de parada, ricamente decoradas con trabajos de ataujía de oro y de plata. En algunos casos, el empleo de estos ricos metales llega a ser exuberante, aunque siempre creando obras de elevado nivel artístico y técnico. Esta riqueza sobrepasa la de las obras italianas contemporáneas que conocemos. El hecho de que parte de estas armaduras viniesen datándose tardíamente, hizo que se considerase la producción de la armería de Eugui como la de un centro provincial influenciado artísticamente por las obras creadas años antes en Italia septentrional. Esta influencia es evidente en tres armaduras de niño destinadas a los hijos de Felipe III (B 13, B 15, B 18) donde encontramos la influencia del sistema decorativo reticular ampliamente usado por el llamado «Maestro dal Castello» (c. 1590-1620); motivo ya empleado poco antes por el «armero regio» Pompeo della Cesa, activo en Milan por los años 1565-1603. También es obvio que los motivos en «S» de una de las armaduras de Felipe III (A 350-353) poseen connotaciones italianas, pero también es cierto que el resto de las obras de Eugui, conocidas documentalmente, encuentran difícilmente un parangón en la producción que llamaríamos milanesa.

Todas estas reminisciencias italianas, más o menos vivas o latentes en los talleres de Eugui, son fáciles de explicar. En efecto, estas obras no fueron realizadas por armeros españoles que se inspiraban o que copiaban más o menos servilmente a sus coetáneos milaneses, si no por un equipo altamente especializado de armeros de Milán que se expatriaron en 1595 siguiendo los deseos de Felipe II (1556-1598) y que fueron enviados a Eugui. Además, dichos armeros se comprometieron a ejercer en España «su oficio de fabricar y Hazer armas de la forma y manera que las hazen y fabrican aqui en Milán» ${ }^{15}$. Si, como es de suponer, cumplieron su promesa, muy difícil será diferenciar una armadura hecha en Milán, en 1595, por estos armeros, de otra fabricada por ellos mismos en Eugui en 1596. Cabe pensar, como es lógico, que un taller de armeros especializados de esta importancia, no viaja con las manos vacías y que traería consigo su «herencia milanesa» con sus riquezas artesanales, técnicas y artísticas, sus libros de patrones, dibujos, croquis y modelos decorativos. Además, estos armeros debieron ser de entre lo mejor existente por esa fecha en Milán, ya que indudablemente, Pedro de Padilla, gobernador interino del Milanesado, desearía cumplir a la perfección la orden de Felipe II dada por carta fechada en Madrid el 16 de abril de $1595^{16}$. El bagaje artístico y estilístico de estos armeros era, en 1595, el de las obras de Pompeo della Cesa, del «Maestro dal Castello», del «Maestro IO dal Castello» y la de otros armeros desconocidos de alto nivel que hacia 1570-1580 dejan sus obras totalmente anónimas o que las «firman» con signos, torres, o diversos tipos de castillos ${ }^{17}$.

El contrato establecido el 20 de julio de 1595 «en el Real y ducal palacio de la ciudad de milan» estipula ${ }^{18}$, en sus trece capitulos, que los armeros deben ir a servir a Felipe II en la corte de Madrid o donde les fuere ordenado durante seis años. Serán obedientes a las órdenes de sus superiores y no dejarán de trabajar ningún día a excepción de las fiestas o debido a un impedimento por causa de enfermedad o por otra razón justificada. El tiempo que dejen de trabajar, sin justificar, les será descontado del sueldo. El salario será de $\mathbf{1 4}$ ducados al mes a partir del día que salgan de Milán y no podrán pretender ningun otro salario; en España, estarán exentos de impuestos. El viaje de Milán a Madrid está a cargo de su Majestad (Felipe II) y reciben un anticipo de 70 ducados que se reparten en dos mitades, la primera a la firma del contrato y la segunda cuando se les mande partir de Milán. Este dinero adelantado se les

15 Archivo General de Simancas, Guerra Antigua, Libro 70, fol. $246^{\mathrm{v}}$.

16 Ibid. Folio $246^{\circ}$.

17 Boccia, Lionello G. y Godoy, José-A. (1992): «Les armures de la garde de Cosimo I et Francesco I de Médicis», en: Genava, n. s., tomo XL, págs 105-108.

18 Ibid, folio $246^{\circ}-249^{v}$. 
descontará del sueldo del primer año. Una vez en España y decidido el lugar de trabajo, recibirán casas para vivir, talleres para trabajar y todos los materiales y herramientas necesarios. Deben, como hemos ya indicado, fabricar las armas del mismo modo que las hacen en Milán y salvo derogación expresa, les está prohibido trabajar directa o indirectamente para cualquier otra persona sea cual fuese su estado o condición.

Las cláusulas de este contrato fueron aceptadas por los armeros a excepción de la relativa al sueldo. Este, fue reajustado como se deduce de la nómina ${ }^{19}$ enviada a España por Pedro de Padilla, el 30 de septiembre de 1595, donde consta el salario mensual y la especialidad de los doce armeros que iban a ir a España: Juan Ambrosio Continuo, grabador (25 ducados); Juan Bautista Seminario, acicalador (20 ducados); Jusepe Piatin, maestro de coseletes (20 ducados); Dionisio Terzago, maestro de brazales (20 ducados); Carlos de Vasin, maestro de celadas y morriones (20 ducados); Ludovico Piatin, ayudante de coseletes (20 ducados); Bernardo de Sasi, armero y dorador (15 ducados); Alberto Vesozo, armero y dorador (15 ducados); Jacome Felipe Lomazo, maestro de manoplas y «de clavar las armas» (14 ducados); Juan de Pedro Ayrago, que «travaja de martillo y ayuda al fuego» (14 ducados); Juan Bautista Grande, ayudante de armero (11 ducados) y finalmente, Bartolomé Comolo, ayudante (11 ducados) ${ }^{20}$. Estos armeros salieron de Milán, todos juntos, el 29 de septiembre, dirección de Génova donde el embajador don Pedro de Mendoza les debía facilitar embarcación para pasar a España ${ }^{21}$. Llegaron a Madrid probablemente entre el 8 y el 14 de enero de 1596, para entonces, ya estaba claramente especificado el lugar donde deberán trabajar: "para pasar a servir en la herreria de Eugui» 22 . Con esta misma designación encontramos citada la localidad de Eugui en documentos de 1598 (fundición de bala de hierro de Eugui) ${ }^{23}$ y 1593 (obras de la fundición de pelotería en la herrería de Eugui) ${ }^{24}$ dirigidos a don Martín de Córdoba y Velasco, virrey y capitán del reino de Navarra. En efecto, desde 1575 la fábrica de Eugui se dedicaba a la fundición de proyectiles de guerra; anteriormente y desde 1496, había allí una ferrería que funcionó hasta 1563. Dicha localidad, situada a 29 kilometros de Pamplona, está enclavada en una zona de grandes arbolados, propicia a la fabricación de carbón y por consiguiente a la instalación de una armería. Su riqueza forestal era tal a finales del siglo XVI «que en solamente las dos endereceras cercanas al pueblo llamadas Ategui e Ilungaran había tal abundancia de árboles, que aunque hubiese tres fábricas y trabajasen de día y de noche sin cesar, no gastarían los árboles de dichas dos endereceras en mil años» ${ }^{25}$. El establecimiento de los armeros italianos en Eugui, en 1596, no parece haber sido una novedad, ya que en un documento notarial de 1589 aparece, entre los obreros de dicha herrería, un Joanes Milán, jurado de Eugui, cuyo apellido evoca su origen milanés ${ }^{26}$.

Las noticias sobre la vida en España de los armeros italianos son escasas y fragmentarias. Sorprende no encontrar traza de las primeras obras creadas por dichos armeros poco después de haberse instalado en Eugui, época en la que seguramente tendrían deseos de mostrar al Rey y al Príncipe el arte que poseían en la fabricación de armaduras. No olvidemos que dichos armeros forman un equipo altamente especializado en este tipo de armas. A partir de las

19 Ibid. Folio $249^{\mathrm{v}}-251^{\circ}$.

20 La mayor parte de los apellidos de estos armeros aparecen diversamente ortografiados en el citado contrato del 20 de julio de 1595: Contino, Seminario, Piato, Tazago, Vezino, Piato, Sapi, Visoco, Lomazo, Ayrago, Tangrande, Comolo.

21 Archivo General de Simancas, Guerra Antigua, Libro 70, fol. $251^{\circ}$.

22 Ibid. Fol. $245^{\mathrm{v}}$

23 Ibid. Libro 51, fol. 6 (29 de marzo de 1589).

24 Ibid. Legajo 375, sin foliar (23 de junio de 1593).

25 SANZ Y BAEZA, Florencio (1858): Historia de la fábrica de Eugui y de la legua acotada, Madrid, pág. 8.

26 HuARTE, Angel de (1927): «Fábricas de armas. Las fábricas reales de Navarra. La armería de Eugui», en: Euskalerriaren, $\mathrm{n}^{\circ}$ 288, págs 444-448; LARRAÑAGA, Ramiro (1981): Síntesis histórica de la armeria vasca, San Sebastián, págs 478-479. 


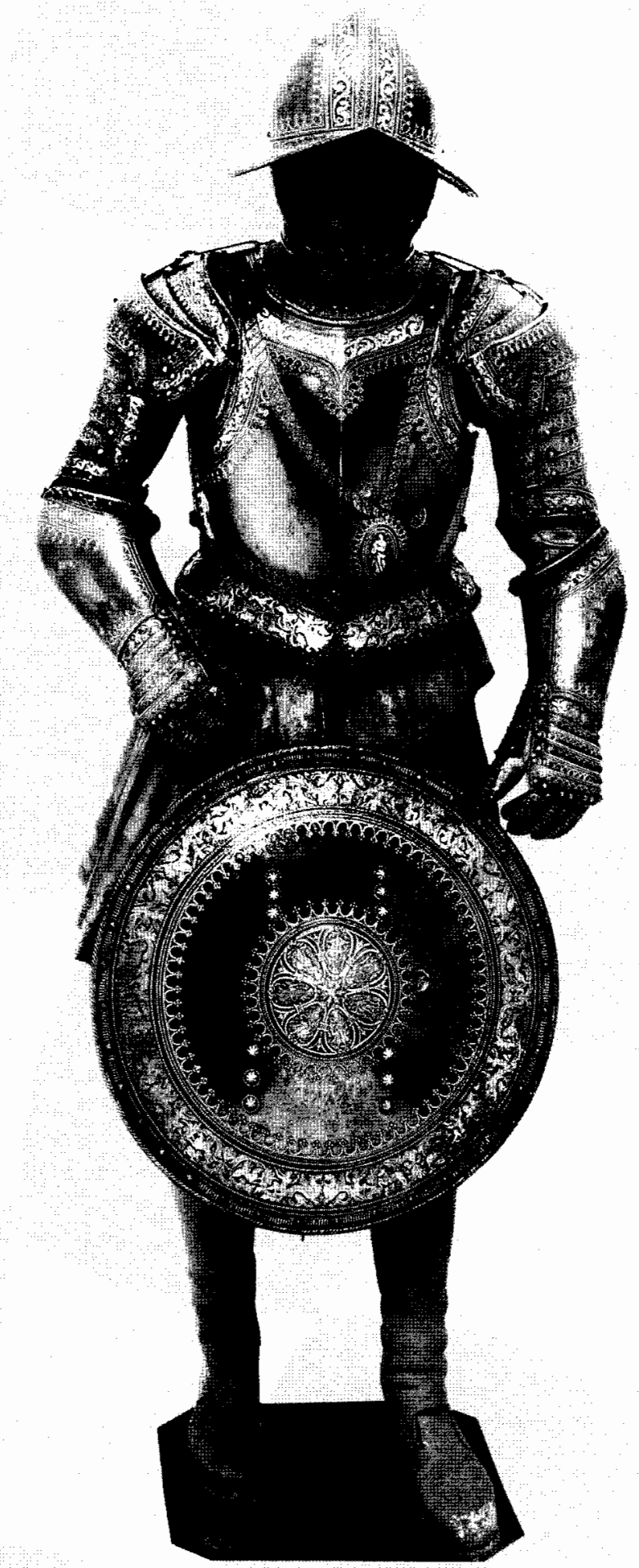

Fig. 3. Armadura y rodela de Felipe III (Madrid, Real Armería, A 354-A 355) 


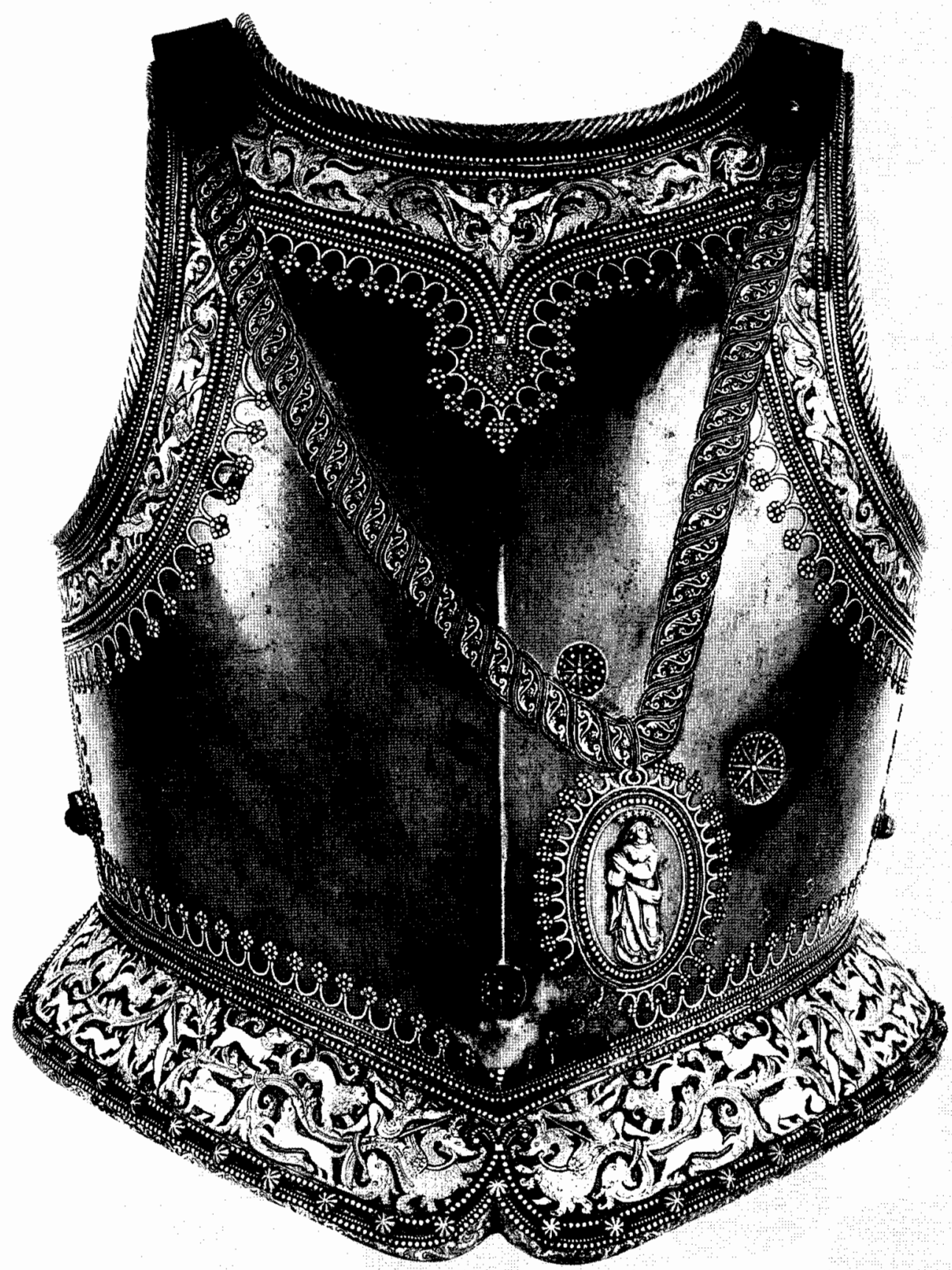

Fig. 4. Peto de la armadura A 354 de Felipe III 
pocas noticias que tenemos, vamos a tratar de dar dentro de lo posible una idea general de la armería italiana de Eugui. El 29 de noviembre de 1601, Felipe III (1598-1621) manda a Antonio Ximenez, pagador de la artillería, que socorra con algún dinero a los cinco armeros y un acicalador que le ha enviado el Conde de Fuentes, gobernador de Milán (1600-1610) para que sirvan en las fábricas de armas del reino de Navarra y vayan a la de «Hegui una de las del dicho Reino» ${ }^{27}$. No podemos con certeza decir si estos armeros vinieron a consolidar el equipo de $1595 \mathrm{o}$, al contrario, a reemplazar la partida de algunos de estos que aprovechando el término del contrato firmado por seis años (29 de septiembre de 1595 - 29 de septiembre de 1601) hubieran deseado regresar a Milán. Sea lo que fuere, mencionemos que estos seis armeros llegaron a la Corte (Valladolid) en un estado lastimoso, como consta claramente en la carta que Felipe III escribió desde Valladolid, el 22 de diciembre de 1601, a Juan de Acuña, del Consejo de Guerra y Capitán General de la artillería: «por parte de los seys armeroles que hultimamente han venido de milan se me ha suplicado que en consideracion del largo camino que an hecho en venir desde la dha milan asta aqui y que por los grandes y excesivos gastos que se les an seguido en el viaje, vienen mal reparados de vestidos y con tanta necesidad que no podran pasar a servir a Navarra donde les haveis ordenado que me vayan a servir les hago mrd [merced] de alguna ayuda de costa con que se puedan abrigar y pagar lo que avran de hazer hasta llegar a la parte donde han de yr [...] deis orden para que a los dhos seis armeroles se le paguen dos mill çiento y treinta reales a rrazon de tres cientos y cinquenta y cinco rreales a cada uno de que les hago mrd (merced) por una ves para los gastos de su viaje desde aqui a Navarra y para se arropen y vistan que tal es mi Voluntad» ${ }^{28}$.

La situación apartada de Eugui hizo que ya desde 1607 y 1612 existiesen tentativas de trasladar la armería a un lugar más propicio. La villa de Tolosa deseó y solicitó acoger dicha armería ofreciendo los terrenos y edificios para su instalación, y comprometiéndose a traer a su costa desde Eugui las herramientas de dicha fábrica. Gracias a estos ofrecimientos, el 12 de enero de 1616, Felipe III dispuso el traslado de la armería de Eugui a Tolosa: «A la noble y Leal Villa de Tolosa / Su Mag a Resuelto que se mude a essa villa Una cassa entera de armeria de los armeros y oficiales que travaxan En el sitio de eugui y como Vm Vera por su carta q ba con esta el principal fundamento que sirvio para tomar este acuerdo fue la oferta $\mathrm{q}$ Vn hizo» ${ }^{29}$. Sin embargo, dicha mudanza tomó su tiempo y el traslado de la armería de Eugui se realizó solamente en 1630, después de haber costado a la villa de Tolosa 9.600 ducados (6000 ducados por la casa, molino, horno y batán; 2000 ducados por la madera; 1000 ducados por los terrenos; 600 ducados por 10.000 fanegas de cal) sin contar el transporte de las herramientas que ascendió a 2000 reales $^{30}$.

La historia de la armería «italiana» de Eugui concluye pues en 1630 , pero la historia de sus armeros se prolonga, un poco más, en la nueva fábrica de Tolosa. El 17 de octubre de 1643 «murio Carlos Vesin maestro mayor destas fabricas por enfermedad de ocho dias», «era muy ombre de bien» ${ }^{31}$. Se trata naturalmente del citado en 1595 como Carlos de Vasin, maestro de celadas y morriones. El puesto vacante desencadenó pretensiones y recelos, y fue codiciado especialmente por el armero español Juan de Piera Gullano y el italiano Felipe Lomaz, quién en la nómina de 1595 aparece como Jacome Felipe Lomazo, maestro de manoplas y de clavar las armas. A través de la correspondencia cruzada con destino a la obtención de dicho cargo y gracias a los ensalces personales, y críticas contra el adversario emitidos por cada uno de los dos candidatos, podemos cubrir algunas lagunas de la historia de la

27 Archivo General de Simancas, Guerra Antigua, Libro 91, fol. $153^{\mathrm{v}}$.

28 Ibid. Fol. 160-161.

29 Archivo de Tolosa, documentación amablemente enviada en fotocopia.

30 Ibid. Ver también Ramiro Larrañaga, op. cit., págs 78-79, 478-479, 501-502.

31 Archivo General de Simancas, Guerra Moderna, Legajo 467, fol. 6-7. Cartas de Domingo de Navia, Tolosa 27 de octubre de 1634 . 
armería de Eugui. El mejor ejemplo de este duelo, lo encontramos ampliamente ilustrado en una carta de Juan de Piera Gullano fechada el 20 de octubre de 1634: «Carlos besin maestro mayor de la armeria a muerto y pues soy español y se açer todo lo que an platicado los ytalianos que es açer armas de a caballo ligero y de ynfante y a prueba de mosquete y arcabuz suplico a $\mathrm{VM}^{\mathrm{d}}[$ [...] se me de titulo de maestro mayor pues soy ynclinado a ensenar a los naturales y los ytalianos ni sus yjos no lo an querido haçer [...] Felipe lomaz es el que lo pretende, bien se que no ara armas acabadas de a caballo pues no sabe acer celadas que es lo mas principal y pues no sabe mal podra enseñar ${ }^{32}$. Esta carta subraya tres temas importantes. El primero concierne al espíritu de casta de los armeros italianos que tratan de guardar celosamente sus conocimientos y secretos de fabricación, transmitiéndolos solamente de padres a hijos o entre italianos, conscientes al hacer esto de que en ello reside su fuerza presente y futura. La divulgación de la cultura artesanal y artística milanesa, hubiera significado irremediablemente, al ser absorbida por aprendices españoles, la decadencia de la hegemonía italiana dentro la armería. El segundo tema evocado, consiste en darnos a conocer el tipo de armas forjadas por los Italianos: esencialmente armaduras a prueba del mosquete y del arcabuz destinadas a la infantería y a la caballería ligera. Y por último, el tercer tema interesante consiste en la reflexión hecha sobre las celadas, considerándolas como la pieza más importante en la fabricación de una armadura. Reflexión que viniendo de un hombre del oficio adquire un cariz particular. No olvidemos que el antiguo maestro mayor, Carlos de Vasin, viene presentado en 1595 como maestro de celadas y morriones.

Una vez conocida la opinión del español Piera Gullano, veamos el punto de vista de la comunidad milanesa encabezada por Felipe Lomaz, quién en 1595, repetimos, aparece como maestro de manoplas y de clavar armas. En una carta dirigada a Ventura de Frías datada en Tolosa el 20 de 1634 (sic), Felipe Lomaz declara: «Carlos Visin maestro mayor de esta armeria es muerto vispera de san Lucas dios le Reziba en su santo Reyn parezeme que ay algun oficial nuebo que pretende ser maestro mayor de esta Armeria Vien save Vmd que quando murio Ludubico piatin me hizo merced en mandar se me diese las llaves del armeria en ausencia del maestro mayor Ofreciendome en hesa Corte de que faltando Carlos Vesin lo seria yo con esso Vine Contento que mas estimo yo su palabra de Vmd que quantas Cosas ay tamvien save Vmd. que yo he servido a su mag . quarenta años con titulo de maestro y soi uno de los fundadores que venimos de milan a fundar esta armeria dejando hacienda y otras obligaciones por servir a su mag ${ }^{\mathrm{d}}$. y he servido el dicho tiempo con aprovechamiento de la Real hacienda Como es notorio y tamvien he sido y soy ynterino [...] en ausencia del $\mathrm{Ma}^{\circ}$ may $^{r}$ de larmeria y hoi estan en mi poder las llaves della. Sup ${ }^{c o}$ a Vmd muy Encarezidamente sea servido que se me aga esta med [merced] de $\mathrm{m}^{\circ}$. may ${ }^{\mathrm{r}}$. de larmeria Con las mismas gracias y preheminencias que tenia mi antezesor Carlos Vesin Considerando mis servicios de quarenta años y con los nuebos deseos que tengo de servir a su mag. ${ }^{d}$ Y de que tengo un hijo en el arm ${ }^{a}$ que se nombra ambrosio Lomaz que de maestros y oficiales no ay quien se le yguale en el ministerio de hazer armas [...] y le dara liçiones en lo Vno y en lo otro [herrajeria] al dho pretendiente ques Joan De pieragullano y ademas de dho anbrosio ai otros dos oficiales que le daran liçiones al dho pieragullano» ${ }^{33}$. En este texto, Felipe Lomaz se presenta como un armero de experiencia puesto que era ya maestro en 1595, y también, como miembro fundador de la armería e interino de ésta en ausencia del maestro mayor; cualidades que pone en relieve al tratar a Juan de Pieragullano de oficial nuevo y al rebajarlo profesionalmente frente a su hijo Ambrosio y dos otros oficiales. Además, con tacto y pertinencia, recuerda la promesa que le había sido hecha de ocupar dicho puesto, y al ensalzar el valor que para él tiene la palabra dada trata de influenciar la decisión final. Por otra parte, los armeros

\footnotetext{
32 Ibid. Fol. 11.
}

33 Ibid. Fol. 23. 


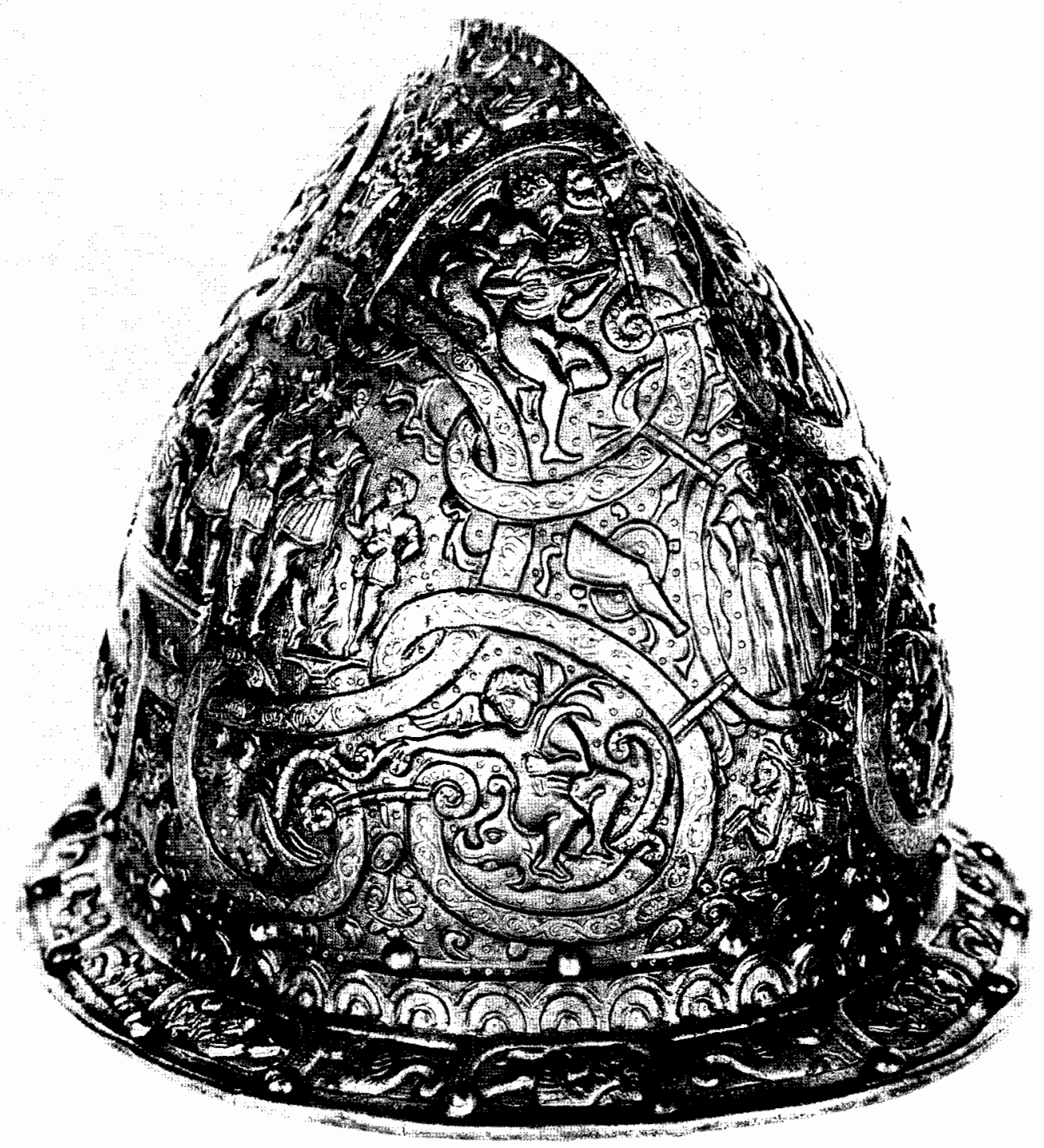

Fig. 5. Capacete de Felipe III (Paris, Musée de l'Armée, H 233) 


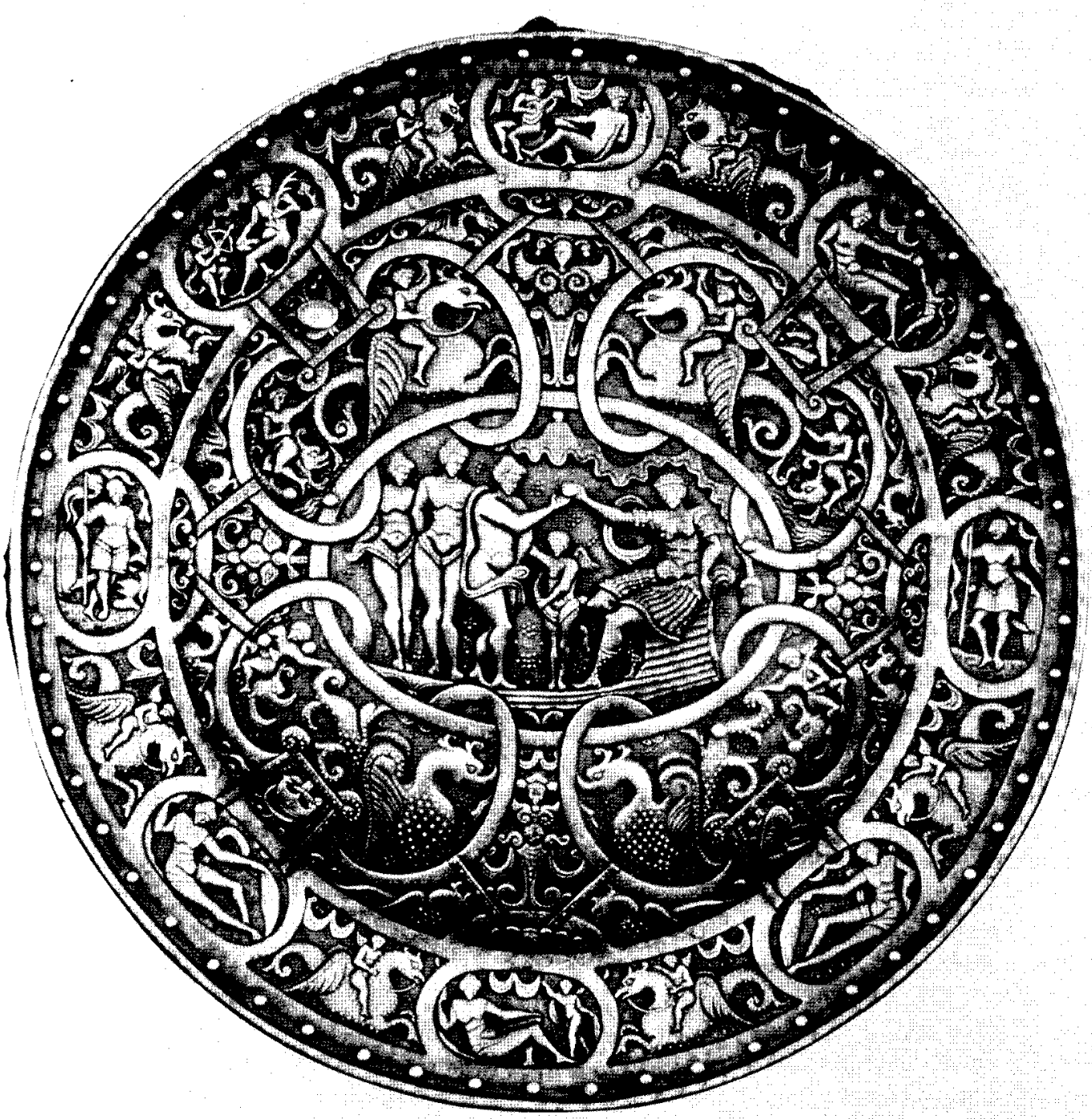

Fig. 6. Rodela de Felipe III (Madrid, Real Armería, D 73) 
italianos lo sostienen haciendo valer sus derechos de antigüedad, opinión que exprime perfectamente Jerónimo Piatin en una carta escrita en Burgos el 23 de octubre de 1634, cuando aún no tenía confirmación de la muerte de Carlos Vesin: «Los mas armeros de tolosa me dicen que carlos bicin Maestro maior de la armeria se esta muriendo i que las llaves de ella las an entregado a feliphe Lomaz para que mande lo que fuere necesario açer para el serbicio de su mag ${ }^{\mathrm{d}} \mathrm{i}$ todos los demas armeros estan muy contentos de que Vmd ala sistutuido a feliphe Lomaz con que quedan muy agradecidos de la merced po ser persona bienemerita i en casso que faleciere el dicho carlos los enportara se continue el oficio en el dicho Feliphe por aber dado a entender Juanpieragullano que a de ser el maestro maior i como el contador francisco dello es apasionado suio podra ser tropelle a la Gusticia i ademas de esso de buena raçon mientras los biejos biben no se les avra de quitar a ellos el oficio pues an venido de sus casas maestros a serbir a su mag ${ }^{\mathrm{d}} \mathrm{i}$ en casso que pudiere tanto pieragullano de alcancar el oficio como el dice abra muy grandes desgracias en larmeria lo qual no permita Dios lu uno de aprendis venir a mandar a los maestros i el otro haber entre los aprendices personas de mas suficiencia que ambrosio Lomaz i no se mete en pretender este cargo [...] yo no lo pretendo para mi por que tengo pocos dias de vida» ${ }^{34}$. Felipe Lomaz no debía ser tan poco capacitado como nos lo presenta Juan de Pieragullano, quién a su vez viene tratado, como hemos visto, de «oficial nuevo» y «aprendis». Además, el capitán Domingo de Navia acabó por nombrarle provisoriamente, en espera de la confirmación y lo presenta como «el mas venemerito y suficiente que ay entre los viejos a lla dispo[sicio]n de V.M.» ${ }^{35}$. Suponemos que acabaría obteniendo el puesto deseado. Sin embargo, aún no lo habia conseguido el 1 de diciembre cuando escribe a Su Majestad: «yo soy y he sido interinario ademas de que Vmd mando que se me diesen las llaves en ausencia del maestro mayor de esta armeria y pues yo soy suficiente para serlo y estoy al cabo de todas las cosas con mis quarenta años de serviçios no seria razon hubiese novedad que yo no he aprendido el ofiçio a costa de su mag ${ }^{d}$. sino que echo maestro me saco de mi casa y pues en el armeria ay mucha paz i quietud como asta aqui $\sup ^{\circ}$. [suplico] a Vmd como a tan gran monarca [...]»36.

Independiente del clima de recelos e intrigas creado por la muerte de Carlos Vecin, la armería de Tolosa efectuaba por entonces tentativas de reestructuración. Ecos de esta situación se encuentran en el memorial que el mismo Domingo de Navia presentó, el 27 de octubre, con el fin de que: «desta manera le vendran a salir las armas a su mag. a precio mas moderado que asta aqui». Entre las proposiciones presentadas destacaremos esencialmente las que atañen a los armeros italianos: «Todos los sueldos que tienen los maestros y oficiales destas fabricas se pueden reducir a que el mayor sueldo sea quince ducados y no mas y el menor siete ducados de los que al presente sirven [...] para la conservacion de las dhas fabricas conbiene reçevir algunos aprendiçes supuesto que an faltado muchos despues que se mudaron y son pocos los oficiales que quedan y se les puede señalar a los dhos aprendices a cinco ducados al mes para que se puedan sustentar / Tambien se advierte que las plaças de ataugia no son ni pueden ser de servi ${ }^{\circ}$ en estas fabricas [...] y porque el dinero que se libra para estas fabricas la mita del llevan las plaças de los viejos que son ya de poco serviçio y las de ataugia que no son de ninguno y los difuntos y otros decretos[?] y no viene despues a quedar lo necesario para los efetivos y compra de materiales y por esto se pasa necesidad» ${ }^{37}$. A parte de las dificultades financieras, la memoria citada presenta la cruel realidad: los tiempos han cambiado y los hombres también. En efecto, los trabajos de ataujía que han hecho célebres las armas y armaduras de lujo de Eugui son considerados en 1634 como inútiles. Esta consideración anuncia el fin de los ricos productos de la armería que trata de sobrevivir

\footnotetext{
34 Ibid. Fol. 12.

35 Ibid. Fol. 6 (27 de octubre de 1634)

36 Ibid. Fol. 25.

37 Ibid. Fol. 29.
} 
y ser competitiva limitándose a la producción de armas en serie creadas bajo los axiomas de simplicidad y eficacidad, y destinadas a alimentar las necesidades de los ejércitos. La decadencia de este centro armero se hace resentir, por una parte los armeros italianos de 1595 son viejos y de poco servicio en 1634, pero tienen un salario elevado; por otra parte, los aprendices son muy escasos. Estos han disminuido desde el traslado de la armería de Eugui a Tolosa. Debemos reconocer que la vida de los aprendices era precaria, ya que ganan apenas para mantenerse. Prueba de ello la tenemos a través del mismo Domingo de Navia, quién declara el 27 de octubre de 1634: «Tambien estos dias a faltado un oficial de los moços de la armeria por no tener mas de quatro ducados de sueldo y no poderse sustentar se a ausentado» ${ }^{38}$. Una nueva prueba de este problema la tenemos a través de Francisco de Elo, administrador de la armería, quién el 6 de noviembre añade: «suplico V.M. se acuerde de los pobres mozos» ${ }^{39}$.

Como hemos visto, sabemos gracias a Juan de Pieragullano que los armeros italianos hacían habitualmente armas, a prueba de mosquete y arcabuz, para la infantería y para la caballería ligera. El mayor número de informaciones sobre la producción de Eugui, nos la vuelve a dar Juan de Pieragullano desde Tolosa el 23 de marzo de 1635. La importancia de esta carta merece que la citemos ampliamente, ya que en ella encontramos detalles sumamente interesantes sobre la fabricación de las armaduras en una época en la que estas tienden progresivamente a desaparecer de los campos de batalla; y también porque nos da una noticia capital sobre una de las primeras armaduras hechas en Eugui. La evolución del arte de la armadura se haya claramente expuesta en dicha carta: «Mucho dias ha que tengo deseos de abisar a Vmd el modo que se tiene en esta armeria para trabajar y lo mucho que sea reformado desde que Fran ${ }^{\text {co }}$. delo (Francisco de Elo) entro administrar larmeria de manera quelas armas oy le estan a su mag ${ }^{\mathrm{d}}$ mas baratas que antes. La raçon es que las golas se haçen solamente con dos pieças que es lo que es platico en la miliçia y se aora el tiempo de dos pieças que llebaba mas y anssi mesmo se a quitado la guarniçion que llababa los braçales gola y escarcelas que iban a la redonda guarneçidas con coreones y pasamano romano y la aforo de las escarçelas y para que bengan mas baratas si Vmd gustare de que no se hagan los brazales enteros tan solamente que lleguen asta el codo ques lo que se platica entre los soldados tanbien debendran baratas a su mag ${ }^{\mathrm{d}}$ hiçiendo las armas negras ya orando la clabaçon que llevan los braçales y escarçelas a la redonda que con esto tendra su mag a mui buen preçio las armas conpustando el sueldo de los que asistimos a trabajar en esta armeria pero como se carga el sueldo de don Juan de Lanz y geronimo peatin y su hijo, y alberto beços que no trabajan en este ministerio y tienen los sueldos crecidos es fuerça que cargando este sobre quelo a las armas bengan mas caras en quanto al peso de las armas es moderado y mas bale que tengan un poco de peso que no que sean tan ligeras que con un quchillo se pueden pasar como son algunas que hay en el catillo de burgos y en ningun tiempo se a trabajado en larmeria tan puntualmente como ahora ni las armas tan a lo platico ansi las de infante como las de a caballo ligero y a prueba de mosquete y arcabuz ques lo que se a platicado desde que binieron los armeros de milan que aunque es berdad que al principio que binieron hisieron una armadura de campo abierto por no se uçar y aber costado muchos ducados mando d. alonso de alfaro no se hisieçen mas y anssi a muchos anos que çeso por ahor no se me ofreçe otra cossa que abisar a Vmd. Cuya bida $\mathrm{g}^{\mathrm{e}}$ nuestro $\mathrm{S}^{\mathrm{r}}$ los anos que puede e yo deseo y desta billa de tolosa a 23 de marzo de $1635 »^{40}$.

Como vemos, dos mundos distintos separan la armadura de campo abierto de 1596, es decir una armadura de a caballo provista de un cierto número de piezas sobrepuestas o de refuerzo que permiten su uso en las justas, y las armaduras de munición de 1635, rigurosa-

\footnotetext{
38 Ibid. Fol. 7.

39 Ibid. Fol. 13.

40 Ibid. Fol. 22.
} 


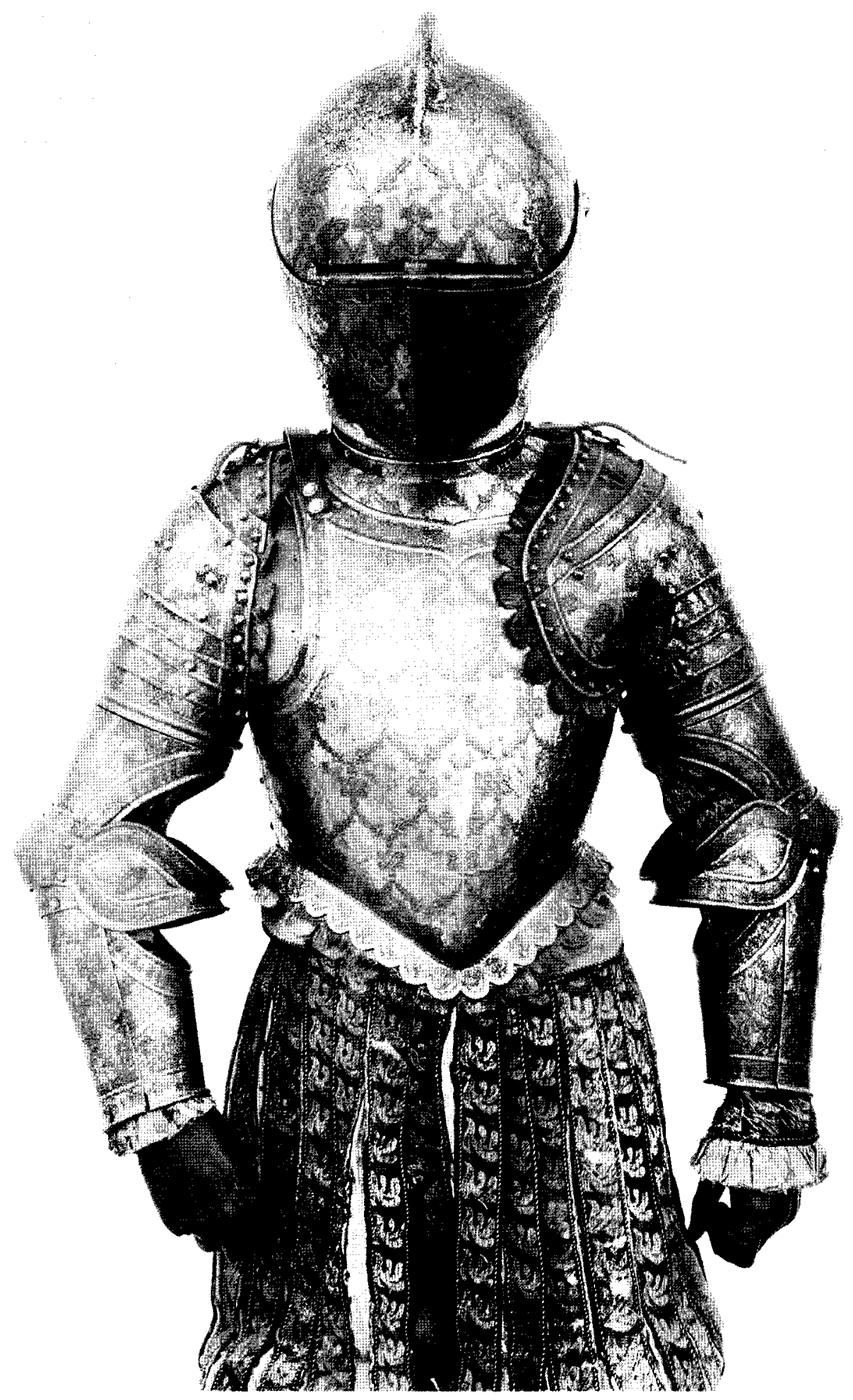

Fig. 7. Armadura pavonada de Felipe IV siendo niño (Madrid, Real Armería, B 13) 


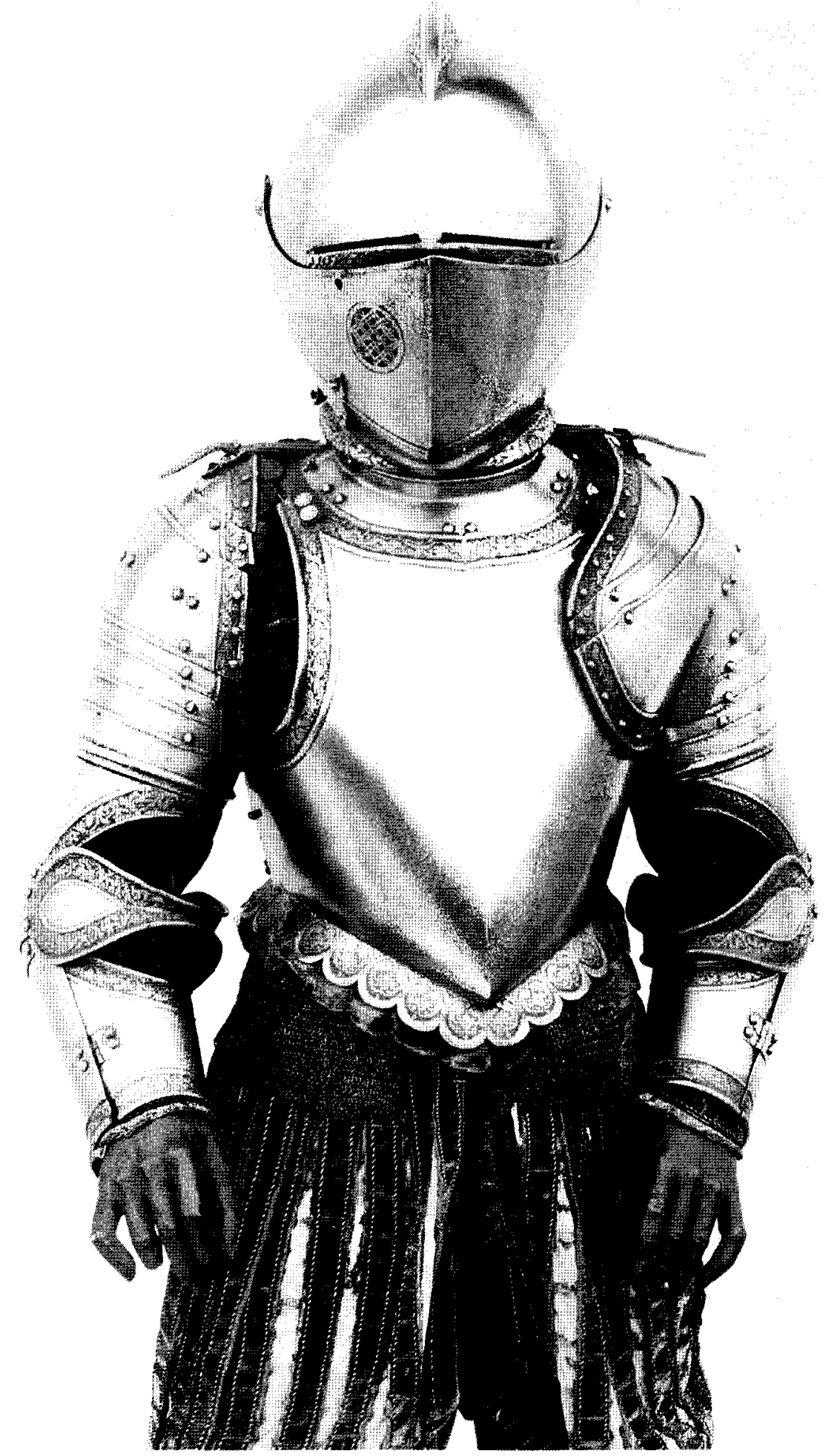

Fig. 8. Armadura de Felipe IV siendo niño (Madrid, Real Armería, B 14) 
mente funcionales, simples y sin guarnición o forros. Al mismo tiempo esta carta evoca la factura deficiente de algunas armas existentes en el castillo de Burgos que se podian atraversar con un cuchillo y, a su vez, plantea el problema del precio de las armas de Tolosa, cuyo coste aún podía ser más barato si no fuera recargado con los buenos sueldos de cuatro personas que no intervenían directamente en la fabricación: Juan de Lanz, Jerónimo Piatin, su hijo y Alberto Beços. Estos dos temas aparentemente ajenos, son en realidad complementarios y constituyen una crítica de las obras y de la situación de Jerónimo Piatin. Efectivamente, éste último parece haberse instalado en Burgos en condiciones actualmente mal conocidas. Recordemos que un Ludovico y un Jusepe Piatin figuran en la nómina de 1595. Ecos de esta situación de revelan en una carta fechada en Burgos el 16 de octubre de 1634, dónde dicho armero se lamenta del comportamiento que con el tuvo don Gregorio Gallo al verlo «ocupado trabajando Por su mag ${ }^{d}$ i no en sus armas doradas resulto muy grande pesadumbre (...) Dijo tenia Licencia De Vmd para que se icieran» ${ }^{41}$, y más adelante, entre otras cosas, menciona la existencia de 600 morriones que quedarían por guarnecer al no haber clavazón en Tolosa. Las relaciones entre Jerónimo Piatin y sus compañeros italianos de Tolosa no debieron ser siempre buenas y si es cierto que apoyó la candidatura de Felipe Lomaz como armero mayor, también es verdad que una comunicación conjunta de los armeros de Tolosa, fechada del 30 de marzo de 1635 , deja claramente establecido las quejas, críticas y recelos que sentían contra él, al haber escrito éste que iba a ir a Milán en búsqueda de armeros. Independientemente de la desconfianza y temor que debieron tener frente a la eventualidad de la venida de nuevos compatriotas, los armeros de Tolosa aprovechan para precisar la buena calidad de sus propios trabajos y dar a entender que si las armas llegan a ser caras, es debido a que al coste de fabricación se agrega el sueldo de Jerónimo Piatin, el de su hijo y el de un capellán mantenido: «Los dias passados escrivio geronimo peatin a personas desta armeria como abia de yr a milan por armeros muy contentos estariamos con esto con que su mag ${ }^{\mathrm{d}}$ nos pagase y se contradecia por otra parte dando alientos para que algunos de aqui dejasemos lo desta armeria y señalando personas para que fuesen a esa corte a trabajar diçiendo tenia ya liçencia para ello y no se contento con solo esto sino que pide por su carta que escribamos a $\mathrm{V}^{\mathrm{a}}$. Ex ${ }^{\mathrm{a}}$. para que benga a esta armeria a poner por asiento las armas muy buen asiento hiciera geronimo peatin pues no sabe que es su mano derecha en fabricar armas suplicamos a $\mathrm{V}^{\mathrm{a}}$. $\mathrm{Ex}^{\mathrm{a}}$. çe sirba de ordenarle nos dege en paz pues nosotros trabajamos continuamente y el dicho geronimo y su hijo sin trabajar sino para si mismo lleban veinta y çinco ducados al mes sin que su mag ${ }^{\mathrm{d}}$ tenga probecho alguno y pues nosotros acudimos al Real çerbiçio con mucho cuidado y desbelo tenemos grande sentimiento de que quien no lo haçe nos traiga siempre enquietos y pues las armas que al preçente se labran en ningun tiempo se an hecho con tanto cuidado y perfecion las cuales bio su $\mathrm{ex}^{\mathrm{a}}$. y conputando el cosste que tienen con las personas que lo travajamos bienen a salir a peçio a como dado pero cargandosele a dichas armas el sueldo de geronimo peatin y su hijo y un capellan entretenido es fuerça que salgan caras y si el sueldo quel dicho geronimo a llebado de diez y seis años a esta parte que como ariba deçimos sea ocupado a trabajar para ssi gozando el sueldo bien se pudiera aber pagado parte de lo que su mag ${ }^{d}$. nos debe y pues esperamos de $V^{a}$. Ex ${ }^{\mathrm{a}}$. el remedio desto no deçimos mas sino que dios $\mathrm{g}^{\mathrm{dc}}$. a su persona feliçes años y desta armeria real de la billa de tolosa a 30 de março de 1635. [Firmado] Felipe Lomazi, Jorge Gand, Juan Bautista Josandy, Batista de Arranoga (?), Pedro de la Tixera, Franciso de Arenas, Juan de Piera Gullano» ${ }^{42}$.

Abandonando estas querellas entre los armeros de Tolosa y Jerónimo Piatin, forzoso es constatar que en ninguno de los documentos citados aparecen mencionadas las ricas armas de lujo elaboradas para la Casa Real en paralelo a la producción de serie destinada a las tro-

41 Ibid. Fol. 10.

42 Ibid. Fol. 17. 
pas. Sin embargo, el hecho de que solamente en 1634 se considerase que «las plaças de ataugia no son ni pueden ser de servicio en estas fabricas», indica claramente que por entonces aún existian y debemos reconocer que estos delicados y costosos trabajos no estarían destinados a embellecer las armas de los soldados, sino más bien las de una clientela selecta y pudiente. Por otra parte, sabemos que el équipo de armeros milaneses de 1595 contaba con dos doradores (Bernardo de Sasi y Alberto Vesozo) y sobre todo con el grabador Juan Ambrosio Continuo, que como hemos visto tenía el sueldo más elevado de todos: 25 ducados. Hasta hoy, las únicas noticias conocidas sobre la producción de lujo de los armeros de Eugui, se encuentran en los Inventarios de la Real Armería de Madrid de 1603/8 y 1625/6:

1603/8: «Un morrion de atauxia, con su Rodela Aforrada en terçiopelo açul y bordado $\mathrm{q}$ trujeron a su mag ${ }^{\mathrm{d}}$. labrada de los Armeros de Eugui en navarra» (pág. 113 ${ }^{\mathrm{v}}$ ).

1625/6: «Mas ay en este caxon seis Arneses pequeños los tres blancos con las orlas doradas y grabadas de Atauxia y aforrados en Raso cabellado bordado con una trençilla de plata y los otros tres Arneses pabonados y quaxados de unos laços de plata y oro y los campos grandes con unos despoxos de guerra y por de dentro plateados y los dhos Seis Arneses se hiçieron por mandado de su Magd. en el Armeria de Panplona y se hiçieron para el serbiçio de su Magd. quando hera prinçipe y de los Serenissimos Don Carlos y don fernando / Dos çeladas sueltas pequeñas blancas con las orlas doradas» (pág. $157^{\circ}$ ).

«Otra Rodela labrada y Relebada de atauxia de oro y plata con su morrion de lo proprio y aforrado y bordado de Rasso carmesi que se hiço en panplona y fue presentada del birrey de Panplona a su Mag ${ }^{d}$. siendo prinçipe en 18 de febrero de $1620 »$ (pág. $162^{\circ}$ ).

«Primeramente un peto y espaldar con escarçelas y quixotes puestas en el con quinçe listas grabadas de Atauxia de plata y oro y otras tantas en blanco y una gola dos braçales con sus guardabraços dos manoplas una çelada y otra con su bentalla una testera de caballo unos açeros de silla un baston de general todas estas pieças de la labor de las Armas forrado todo en terçiopelo carmesi y guarneçido con almenillas de dho terçiopelo y todo con galon de oro al canto / Una guarniçion de espada y daga de la misma labor y talabartes y espuelas y tornillos para los açeros de la silla y dos goçetes de Malla con las orlas de terçiopelo carmesi con galon de oro» (pág. 178 ${ }^{\circ}$ ).

«Otros Arnes fuerte pabonado y las orlas doradas y plateadas de Atauxia que tiene peto con banda y al Remate della una Ymagen de nra Senora de la conçepçion y un espaldar y gola con un collar de oro de Atauxia en que esta pendiente el tuson de oro con dos medios braçales fuertes que llegan hasta el codo y dos manoplones largos y un Morrion y una Rodela fuerte todo guarneçido de terçiopelo carmesi con sus almenillas y galon de oro por los cantos, este Arnes y el Anteçedente se hiçieron en pamplona y se entrego en el Armeria de doçe de março de 1620 de que dio Reçibo Juan de cueço Armero de su Mag ${ }^{\text {¿ }}$ (pág. 178 ${ }^{\circ}$ ).

«Un Arcabuz de Mecha con su frasco y polborin labrado todo de Atauxia y una bolsa con tres bolsillos de Raso carmesi bordado a lo largo de cordones de oro que lo ynbio el birrey de nabarra a su Mag ${ }^{\mathrm{d}}$. de Philipe $4^{\circ}$. siendo prinçipe y se ynbio a esta Armeria por el conde de Saldaña Siendo su caballerico Mayor» (pág. 178 ${ }^{\circ}$ ).

La mayoría de las armas citadas en estos inventarios se han conservado hasta nuestros dias y la casi totalidad de ellas se encuentran en la Real Armería de Madrid. Salvo mención particular, las piezas que presentamos a continuación figuran en esta colección. 


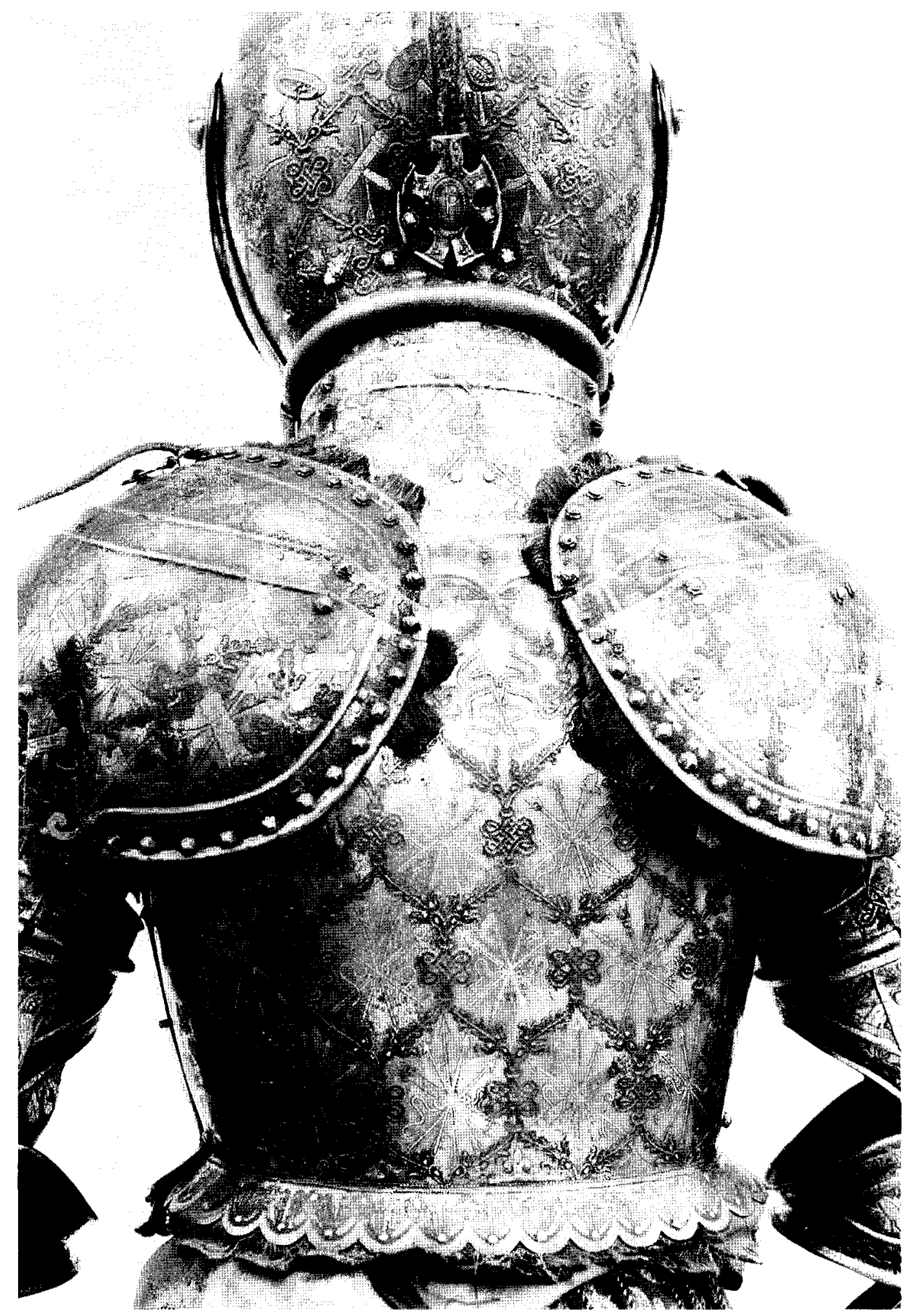

Fig. 9. Detalle de la armadura B 13 de Felipe IV 


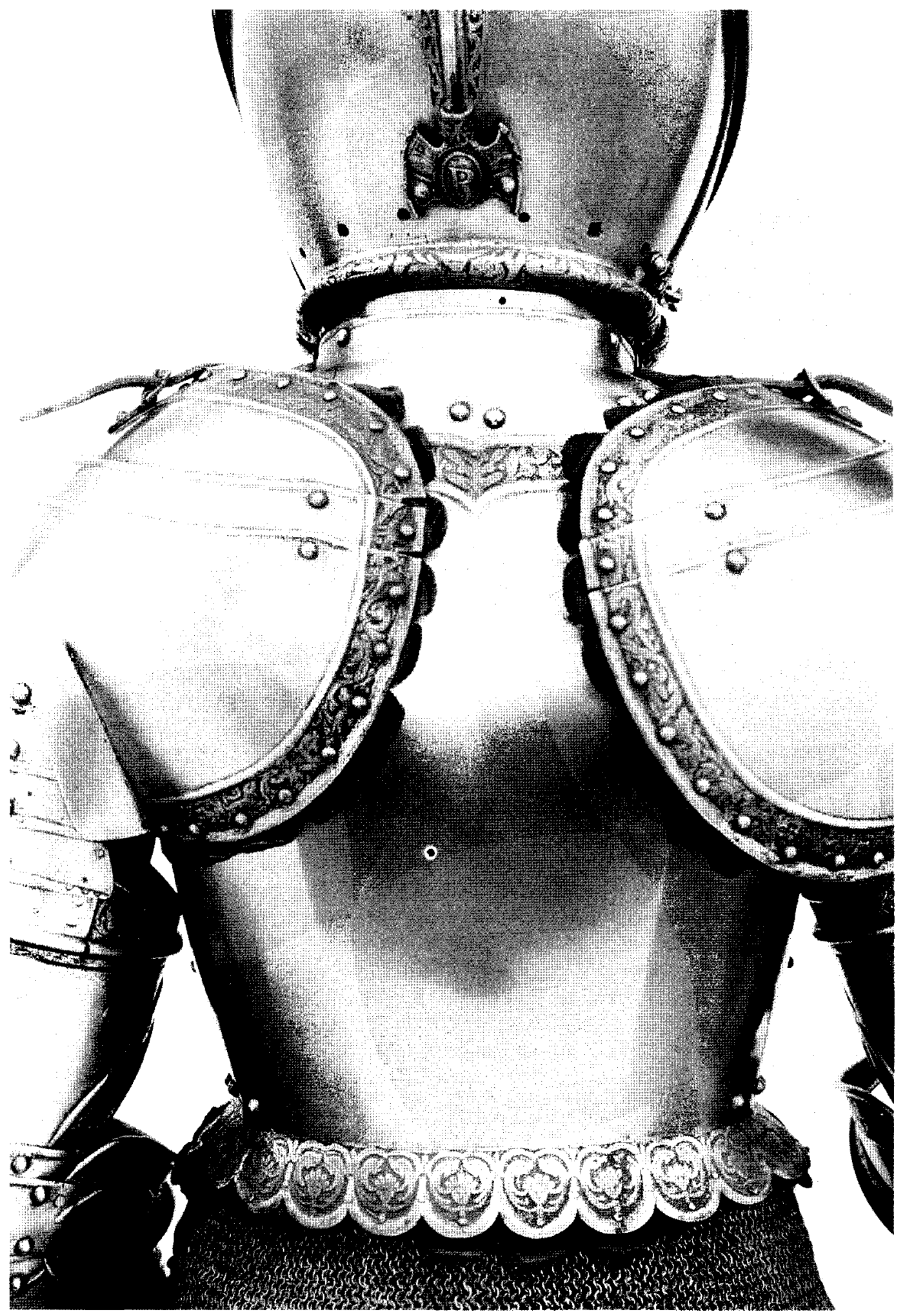

Fig. 10. Detalle de la armadura B 14 de Felipe IV 
De los dos juegos de morrión y rodela mencionados respectivamente en 1603-1608 y 1620, sólo uno de ellos tiene bastantes posibilidades de haber sido identificado. Valencia de Don Juan menciona solamente uno de estos conjuntos, ya que al tratar de la rodela $\mathrm{D} 73$ la presenta como «labrada por los armeros de Eugui, en Navarra». Es decir, que emplea casi las mismas palabras que encontramos en el inventario a propósito de la rodela y del morrión que ingresaron en la Real Armería entre 1603 y finales de julio de 1608: «labrada de los Armeros de Eugui en navarra». En cuanto al morrión, dicho autor especifica juiciosamente que «El morrion compañero de esta rodela [...] hoy está en el Museo de Artillería de París, rotulado H. 233». En efecto, esta pieza ${ }^{43}$ (fig. 5) es estilísticamente compañera de la rodela D 73 (fig. 6) y además forma parte de las armas desaparecidas de la Real Armería, puesto que lleva marcado en la zona del portapenacho «D. 29. N. 23», número de inventario que corresponde al sistema establecido en tiempos de Ignacio Abadía (1793), y que quiere decir: División 29, Número $23^{44}$. Independientemente del extraño vocabulario ornamental empleado con dragones, grifos, etc, la labor en relieve de las escenas figurativas del morrión y el Juicio de Paris en la rodela, sitúa estas piezas más bien a finales del siglo XVI que hacia 1620. De aquí que, por eliminación, optemos por relacionar este juego de rodela y escudo con el documento de 1603/8. Sin embargo, este conjunto dataría de algunos años antes y visto que en el citado documento no se especifica, como ocurre en los otros textos, que su Majestad (Felipe III, 1598-1621) era príncipe, podríamos avanzar la fecha de 1598-1603/8. Referente a la rodela y morrión presentados al futuro Felipe IV, el 18 de febrero de 1620, por el Virrey de Pamplona, ignoramos tanto su paradero como su forma y motivos decorativos.

Otra pieza enviada por este mismo virrey a Felipe IV siendo príncipe, es decir antes de 1621, es el arcabuz de mecha K 6 ricamente trabajado en ataujía tanto en la llave como en el cañón que acaba en cabeza de dragón con cara humana ${ }^{45}$ (figs 13-14). Entre los motivos decorativos, señalemos la presencia sobre la recámara del cañón de medallones ovalados, de los cuales uno con águila biceps coronada, y sobre la lengüeta de la recámara un motivo indeterminado que hizo pensar en la marca de los fabricantes. Carecemos de pruebas para poder afirmar o negar esta aserción que en el caso de ser cierta, debería limitarse a la marca del armero autor de la decoración puesto que la marca de fabricación del cañón se encuentra en la culata, invisible desde el exterior (fig. 14a-b). Esta marca puede atribuirse con un cierto fundamento a los armeros de Eugui, a menos que al no ser especialistas en armas de fuego, hubiesen utilizado un cañón forjado en otra localidad. El frasco, el polvorín y la bolsa con tres bolsillos compañeros de este arcabuz y citados con él en el inventario, no se han conservado.

En cuanto a las seis armaduras de niño y las dos celadas, se trata del conocido grupo B 13-20 de la Real Armería de Madrid. Estaban destinadas, como claramente se especifica en el inventario, a los tres hijos de Felipe III, don Felipe, don Carlos y don Fernando. Cada uno de ellos recibió dos armaduras de torneo de a pie similares a las de los dos otros hermanos. Una de estas armaduras, la más rica (figs $7,9,11$ ), está pavonada de azul con el campo

43 L'Haridon, Penguilly (1867): Album du Cabinet d'Armes de Sa Majesté l'Empereur Napoléon III, París, pág. 34, $\mathrm{n}^{\circ}$ 167, fig.; ROBERT, L. (1890): Catalogue des collections composant le Musée d'artillerie en I889, t. II, París, pág. 205.

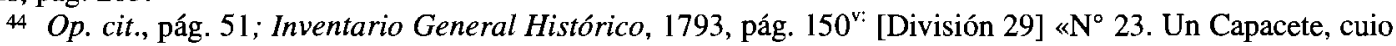
fondo en general es dorado y graneado y sobre el varios cartones enlazados formando diferentes estancias, en las de los laterales, $q^{\mathbf{e}}$. son las maiores, se ven al derecho de reliebe, figuras de Soldados $\mathrm{q}^{\mathbf{e}}$. presentan un Prisionero, à un Heroe $\mathrm{q}^{\mathrm{e}}$. esta sentado, dos Niños y una Ara de fuego; al izquierdo, un soldado arrodillado delante de una figura $q^{e}$. parece de muger y $q^{e}$. está en accion de mandarle, dos Soldados, un Niño mas y un Cavallo, y sobre todo esto en la parta una nube y dentro de ella la Virgen con el Niño Dios en los Brazos. Son sin duda dos pasages de Historia $q^{e}$. no ha podido inferirse quales sean. En las otras estancias $q^{e}$. resultan hai una Judit, diferentes Marthes, un Heroe à Cavallo, Genios, Dragoncillos, Cariatides y otros adornos, todo de reliebe y de mui mal gusto, con algunas porciones doradas, y en general tachonado de pequeñas perlas de oro y plata».

45 Largo del cañón: $997 \mathrm{~mm}$; calibre: $16.5 \mathrm{~mm}$. 
reticulado, a base de nudos decorativos, conteniendo trofeos de armas a excepción del peto que lleva también un castillo, un león heráldico, las columnas de Hércules y un águila biceps; estos cuatro motivos están sobremontados de una corona. El cuello y el borde de las axilas están adornados con el collar del Toisón. La segunda armadura es más sobria (figs 8 , $10,12)$, con el campo liso color acero y decorada en los bordes con una estrecha banda cincelada y dorada con ramajes acabando en cabezas de animal, humanas o mostruosas, que acogen figuras humanas, pájaros, leones, perros, etc. Los portapenachos de las celadas llevan las iniciales de los proprietarios: una P (Philippus) en B 13 y B 14; una C (Carolus) en B 15; una F (Ferdinandus) en B 18. Las celadas B 16-17, B 19-20 no tienen el portapenacho original o carecen de él. Cada armadura o algunas de ellas debía tener dos celadas, pero esto no se especifica en el inventario donde dichos arneses se citan en bloque, a excepción de «dos celadas sueltas pequeñas blancas con la orlas doradas» que corresponden a las celadas B 17 y B 20 semejantes a las de las armaduras B 14, B 16 y B 19. Una prueba de ello, la tenemos en la existencia de las celadas E 14 y E 15 de la Armeria Reale de Torino ${ }^{46}$ que pertenecen a las armaduras pavonadas B 15 y B 18 y que llevan respectivamente en los portapenachos una $\mathrm{C}$ y una F. Ninguna de las seis armaduras de la Real Armería conserva los guantes. De las armaduras pavonadas subsisten un par de guantes y dos guantes derechos en el Victoria \& Albert Museum de Londres (1386-1888; M 304, 304 A-1919) ${ }^{47}$; y otros dos guantes izquierdos en el Museo del Ermitage a San Petersburgo (Z. O. 3065-3066). Mientras que de las armaduras blancas hay dos pares de guantes en el Metropolitan Museum of Art de Nueva York (14.25.897; 14.25.898; 22.147.9). Algunos de estos guantes están incompletos. Las cara interior de las armaduras conserva restos del baño de plata indicado en el inventario: «por de dentro plateados». Todas ellas datan de hacia 1614 y corresponden respectivamente a niños de 9,7 y 5 años.

Referente a la armadura «con quince listas grabadas de Atauxia de plata y oro y otras tantas en blanco», se conservan la mayoría de las piezas señaladas: armadura de a caballo (figs 1-2) con dos celadas; una de las dos espuelas; la testera y los aceros de la silla (A 350353 ; F 170). Aunque no aparece mencionada en el inventario, la rodela C 1997 del Oberösterreichisches Landesmuseum de Linz pertenece indudablemente a esta armadura ${ }^{48}$. Todas las piezas están ricamente decoradas en ataujía con festones, tarjetas y « $S »$ derechas e invertidas; y en lo alto del peto, la imagen en plata dorada de la Inmaculada Concepción. La superficie interna de las celadas presenta un baño de oro, mientras que la del resto de la armadura tiene trazas de un baño de plata semejante al de las armaduras de niño. Además, en tiempo de Martínez del Romero (1849), la celada A 350 tenía «un porta-plumas en figura de águila imperial coronada, con un escudo de armas de España ${ }^{49}$. Esta armadura perteneció a Felipe III y no estaba destinada al duque Carlos Manuel I de Saboya como lo pensó Valencia de Don Juan ${ }^{50}$. Tampoco data de 1620, como se pensó bajo la influencia de la fecha indicada en el inventario de 1625/6: «se entrego en el Armeria en doçe de março de 1620». En efecto, esta fecha corresponde a la de la entrada de las piezas en la Real Armería y no a la de su fabricación. Personalmente pensamos que podría haber sido ejecutada con motivo de su subida

46 ANGEluCCI, Angelo, op. cit., págs 173-174; HAYWARD, J. F. (1965): Victoria \& Albert Museum. European Armour, London, $\mathrm{n}^{\circ} 37$; Dondi Giorgio y CARTESEGNA Marisa, op. cit., pág. 344, $\mathrm{n}^{\text {os }} 72$ y 73.

47 HAYWARD, op. cit.

48 Thomas, Bruno; Gamber, Ortwin; Schedelmann, Hans (1963) :Die Schönsten Waffen und Rüstungen aus europäischen und amerikanischen Sammlungen, Munich, $\mathrm{n}^{\circ} 72$; edición italiana: Armi e armature europee, Milano, 1974, pág. 274, fig. 213; Thomas, Bruno (1966): Die Sammlungen des Scholssmuseums Linz, Linz, pág. 58, fig. 25; Boccia, Lionello G. y CoElho, Eduardo T. (1967): L'arte dell'armatura in Italia, Milano, pág. 465466; GRANCSAY, Stephen, V. op. cit.

49 Op. cit., pág. $188, \mathrm{n}^{\circ} 2488$.

50 Op. cit., págs. 104-105. 


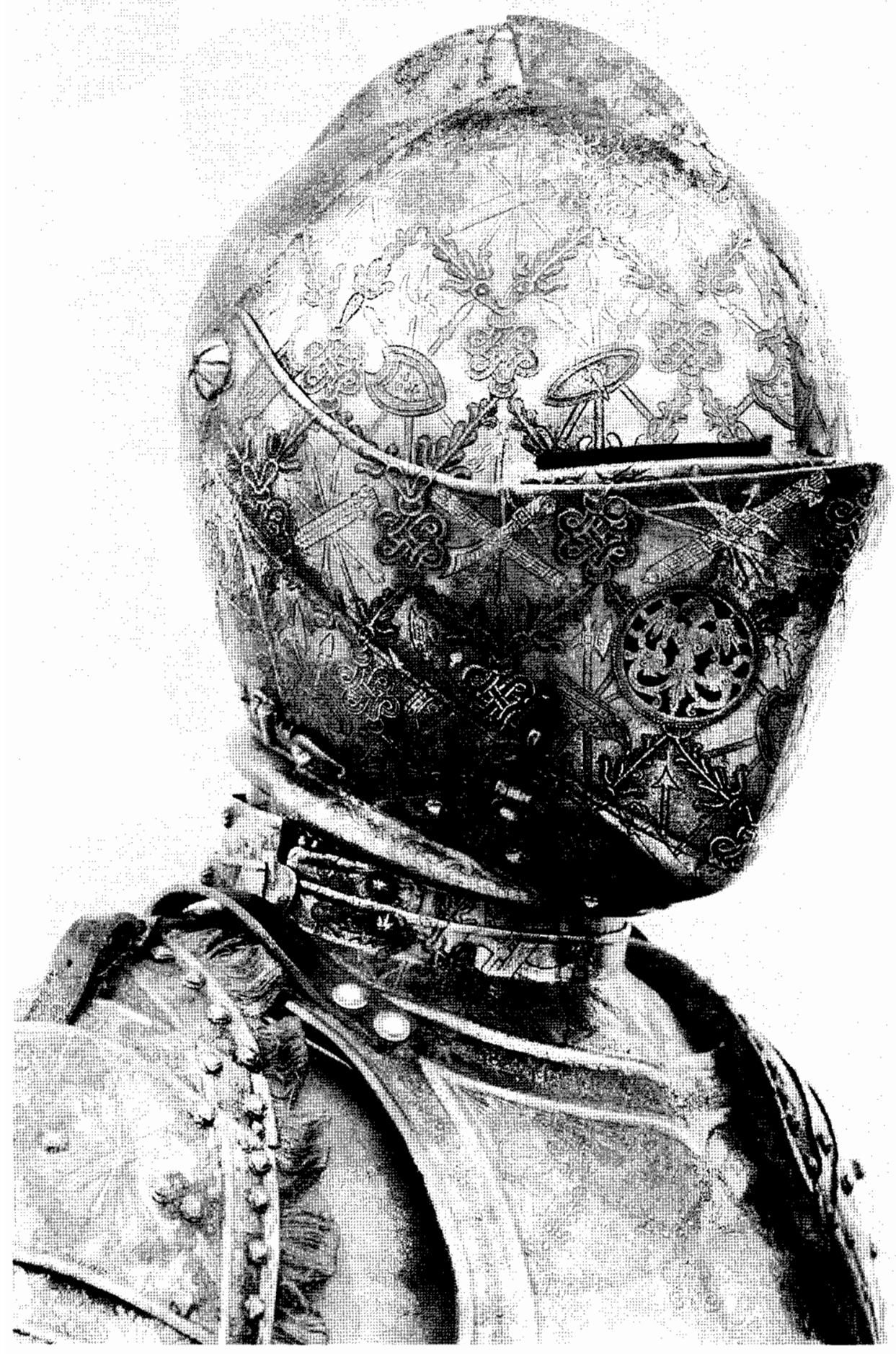

Fig. 11. Celada de la armadura B 13 de Felipe IV 


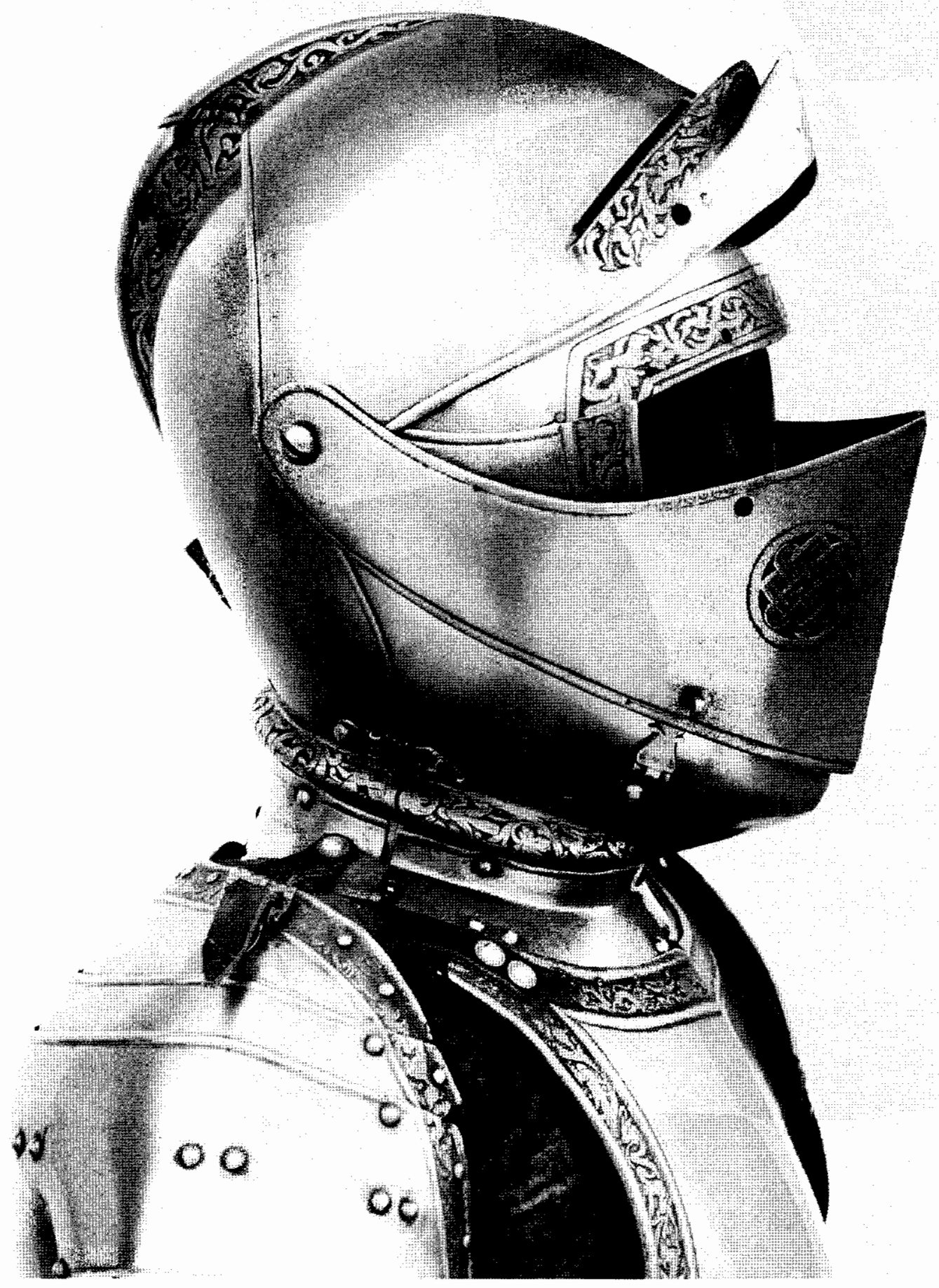

Fig. 12. Celada de la armadura B 14 de Felipe IV 

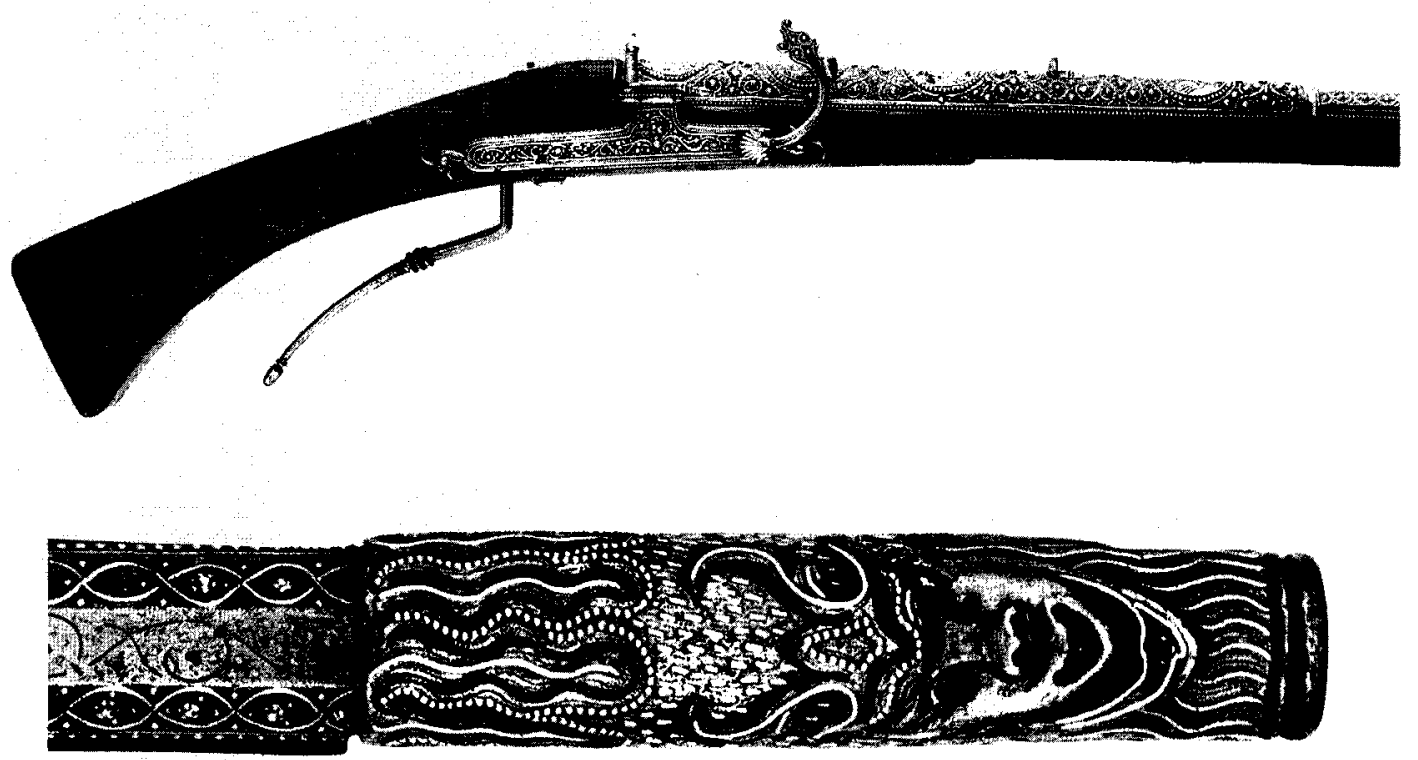

Fig. 13-14a

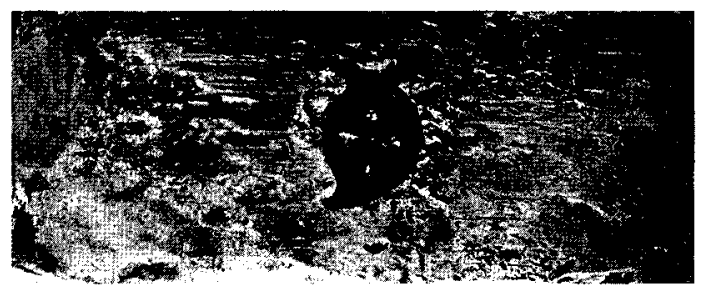

Fig. 14a

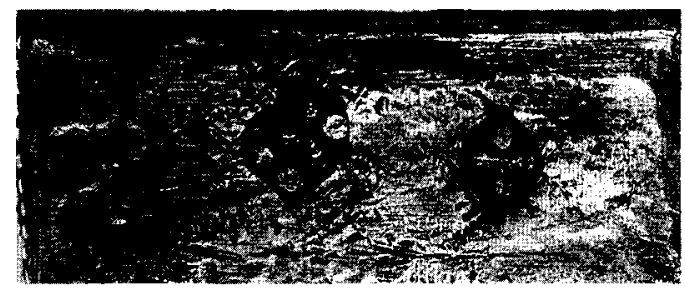

Fig. 14b

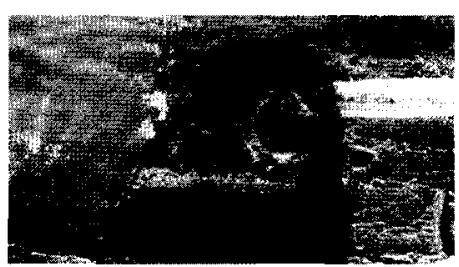

Fig. 15a

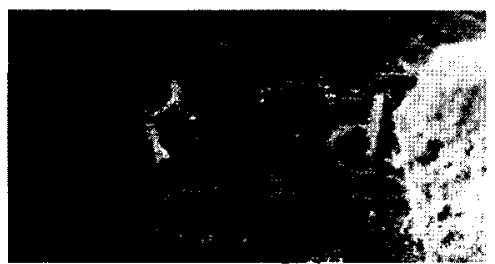

Fig. $15 b$

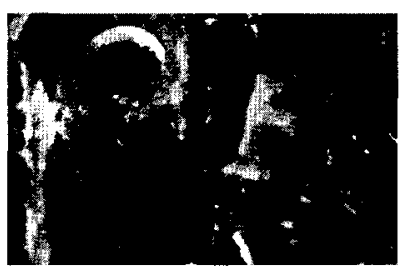

Fig. $15 \mathrm{c}$

Fig. 13. Arcabuz de mecha de Felipe IV (Madrid, Real Armería, K 6)

Fig. 14. Detalle de la boca del cañón y marcas del arcabuz K 6

Fig. 15. Marcas de los armeros italianos de Eugui (Madrid, Real Armería, B 13-14, B 16, B 18-20) 
al trono en 1598 o de su boda en 1599 con Margarita de Austria. Esta boda se celebró conjuntamente con la del archiduque Alberto VII (1599-1621) y la infanta Isabel Clara Eugenia, y recordemos, dentro de esta hipótesis, que existe una armadura del Archiduque decorada con $« \mathrm{~S} »$ derechas e invertidas que se supone fue forjada también para esta ocasión ${ }^{51}$.

La última armadura documentada, el "Arnes fuerte», se conserva completa en la Real Armería (A 354-355). La corona y siglas grabadas sobre el portapenacho del capacete muestran claramente que perteneció a Felipe III: «P.H.S.R. III» (Philippus III Rex). Se trata de una rica armadura tipo asedio de plaza que pesa unos $41.280 \mathrm{~g}$. y que se acompaña de una rodela pesadísima de 22.675 g. (figs $3-4$ ). Tanto el capacete, como el peto y la rodela han recibido la prueba de balas, y las marcas producidas han sido finamente decoradas con los motivos allí existentes o con estrellas de ocho puntas. El campo de las diferentes piezas está pavonado de azul, con los bordes enriquecidos con festones lobulados de plata en relieve o con bandas cinceladas a base de hojas onduladas donde aparecen animales, mostruos y figuras humanas. Destaquemos entre los otros motivos decorativos: un collar con la imagen de la Inmaculada Concepción en el peto; el collar del Toisón en la gola y las Siete Virtudes Cardinales en el umbo de la rodela. Esta armadura viene datándose, como la anterior, hacia $1620^{52}$, pero nos parece mejor situarla alrededor de 1614 ya que el vocabulario ornamental utilizado en las bandas cinceladas (ramajes, animales, mostruos y figuras humanas) presenta algunas concordancias estilísticas con el empleado en las armaduras de niño B 14, B 16-17 y B 19-20.

Los armeros italianos de Eugui demuestran en estos trabajos destinados a Felipe III y a sus hijos que, independientemente de las armaduras de munición destinadas a la infantería y a la caballería ligera, eran capaces de crear obras de elevado nivel artístico. Ignoramos la amplitud de las armas y armaduras de lujo realizadas en este centro armero durante los 38 años comprendidos entre 1596, momento de la instalación en Eugui de los armeros milaneses, y 1634 cuando se considera que las plazas de ataujía no son de ninguna utilidad. Debemos reconocer también que fuera de un cierto criterio de riqueza, basado en una predilección por las labores de ataujía de oro y de plata, desconocemos las características de la producción selecta de Eugui y en algunos casos, es y será difícil de calificar ciertas obras como un producto «milanés» de Eugui o «milanés» de Milán. En cuanto a las armaduras de munición, su identificación es actualmente prácticamente imposible.

Señalemos por último, que algunas de las armaduras de niño están marcadas en el interior, en puestos poco visibles, con pequeños signos correspondientes a diversos armeros. Se trata, respectivamente, de una $\mathrm{C}$ o de una media luna; de una $\mathrm{P}$; $\mathrm{y}$ de una cruz latina privada de su brazo izquierdo cara al espectador (fig. 15a-c). La primera marca, figura en el barbote y calva de la celada, gola, peto y espaldar de la armadura B 14. La segunda, en la gola, peto y espaldar de la B 16; el espaldar de la B 13; y en el barbote y calva de la B 19. La tercera, en el barbote y calva de la celada, y peto de la B 18; el ventalle de la celada, gola, peto y espaldar de la B 19; y la vista de la celada B 20. El hecho de haber encontrado recientemente estas marcas ocultas, durante una revisión parcial fortuita, nos impide hoy ser exhaustivos. Por ello, no excluimos la existencia de estas o de otras marcas en el resto de las piezas documentadas de Eugui. De ser así, volveremos sobre el tema. De momento, dos de estos signos pueden atribuirse a algunos de los armeros citados. Considerando la costumbre de los armeros milaneses, las marcas deben corresponder en primer lugar al nombre del maestro armero y, en su defecto, al apellido. Recordemos dentro de este contexto el caso del citado

51 DESTRÉE, Joseph (1888): «L'armure de parade de l'archiduc Albert», en: Annales de la Société d'Archéologie de Bruxelles, 1888, págs 6-10; BOEHEIM, Wendelin (1894): Album hervorragender Gegenstände aus der Waffensammlung des Allerhöchster Kaiserhauses, Wien, vol. I, págs 18-19, lam. 34; GAMBER, Ortwin: (1958) «Der italienische Harnisch im 16 Jahrhundert», en: Jahrbuch der Kunsthistorischen Sammlungen in Wien, vol. 54, pág. 109, fig. 119; THOMAS, Bruno y GAMBER, Ortwin, op. cit., págs 821-822.

52 Thomas, Bruno y GamBer, Ortwin (1958): op. cit., pág. 826. 


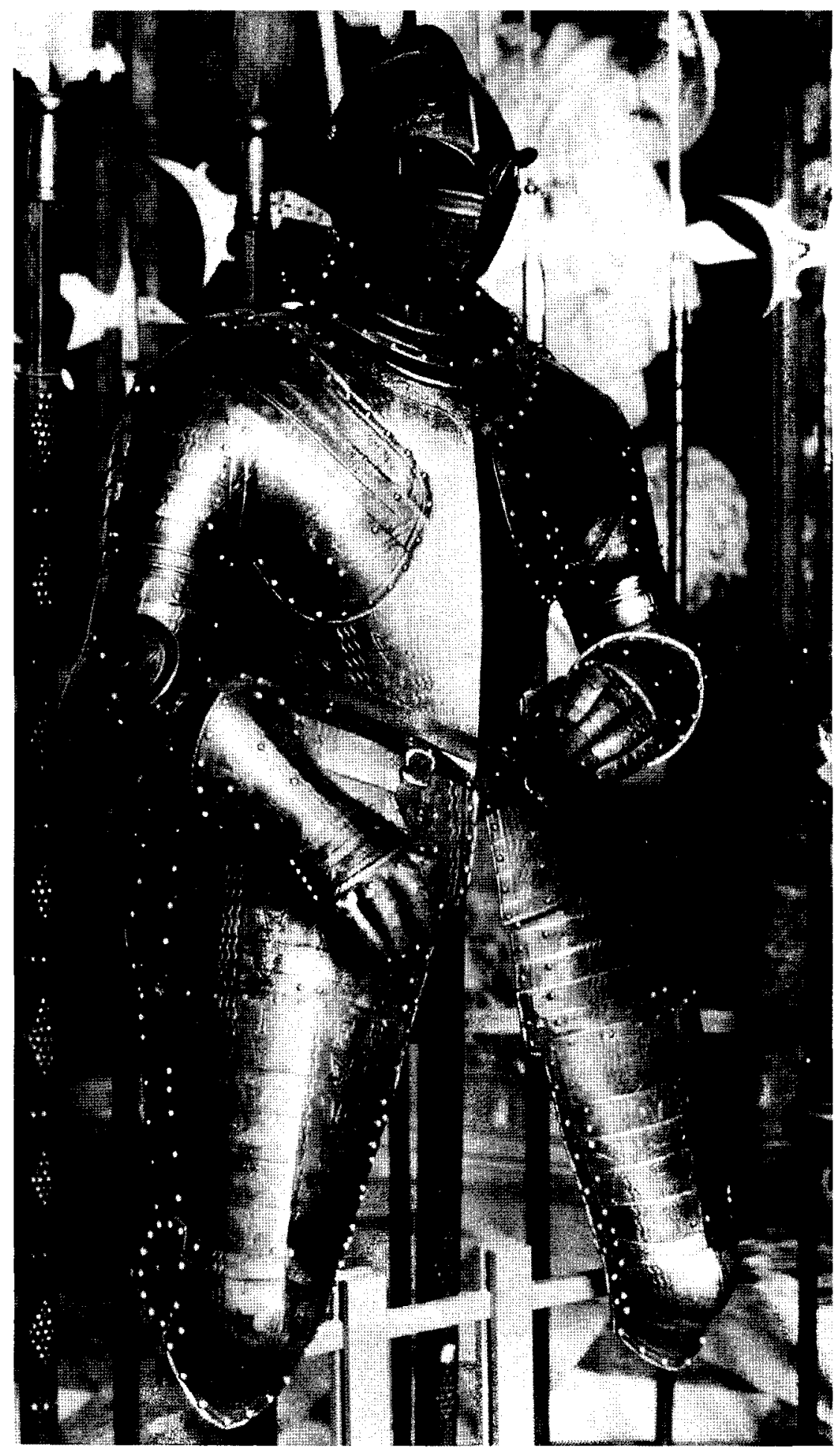

Fig. 16. Armadura de don Gómez Suárez de Figueroa y Córdoba, Duque de Feria. Armería Reale de Torino (B44). 


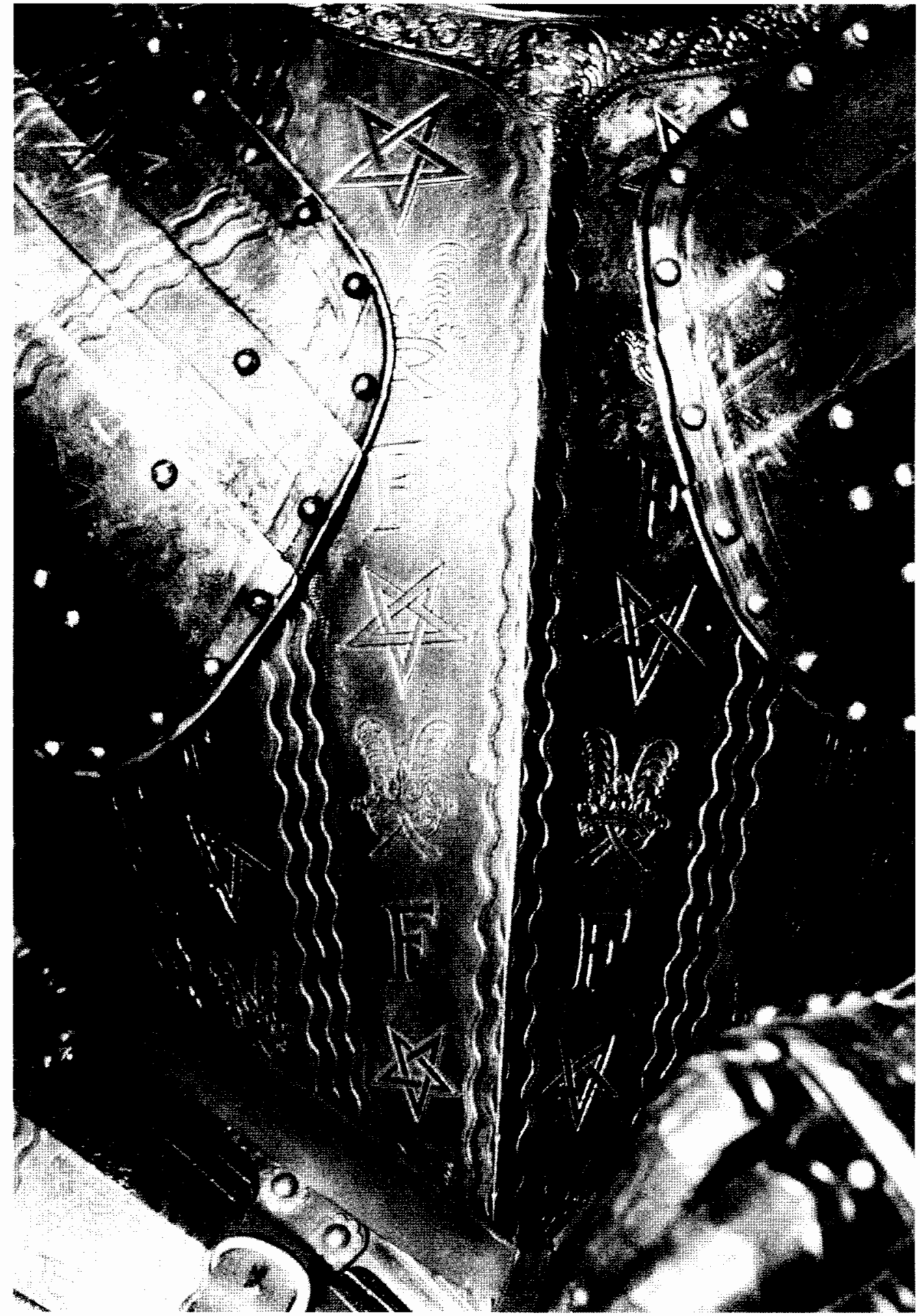

Fig. 17. Peto de la armadura del Duque de Feria 
Pompeo della Cesa, activo en Milán hacia 1565-1603, que firma generalmente POMPEO, POMPE, POMP e incluso con una simple P como en el peto C 71 de la Armeria Reale de Torino ${ }^{53}$. Según esta regla, la $\mathrm{C}$ debería corresponder a Carlos de Vasin o Vezino maestro de celadas y morriones ${ }^{54}$, y la $\mathrm{P}$, eventualmente - a falta de un nombre empezando por esta letra - a Jusepe Piatin o Piato, maestro de coseletes. En cuanto a la tercera marca, que es más bien un signo que una letra, carecemos de paralelos para su atribución a uno u otro de los maestros armeros restantes de la armería de Eugui.

\section{JosÉ-A. GodOY}

Conservateur des Armures et des Armes Anciennes. Musée d'Art et d'Histoire

2 rue Charles - Galland -1211 Genève

53 GoDOY, José-A. (1984): «Emmanuel-Philibert de Savoie (1528-1580): un portrait, une armure», en: Genava, n. s., tomo XXXII, págs 84-86, fig. 21.

54 No creemos que la $\mathrm{C}$ pueda aplicarse a Juan Ambrosio Continuo o Contino, grabador, ni a Bartolomeo Comolo, ayudante. 